\title{
EVALUATING THE GERMAN INVENTORY CYCLE - USING DATA FROM THE IFO BUSINESS SURVEY
}

\author{
THOMAS A. KNETSCH
}

CESIFO WORKING PAPER NO. 1202

CATEGORY 5: FisCAL POLICY, MACROECONOMICS AND GROWTH

MAY 2004

Presented at CESifo Conference “ACAdemic Use of Ifo Survey DatA"

DECEMBER 2003

\footnotetext{
An electronic version of the paper may be downloaded

- from the SSRN website: www.SSRN.com

- from the CESifo website: www.CESifo.de
} 


\title{
EVALUATING THE GERMAN INVENTORY CYCLE - USING DATA FROM THE IFO BUSINESS SURVEY
}

\begin{abstract}
Inventory fluctuations are an important phenomenon in business cycles. However, the preliminary data on inventory investment as published in the German national accounts are tremendously prone to revision and therefore ill-equipped to diagnose the current stance of the inventory cycle. The Ifo business survey contains information on the assessments of inventory stocks in manufacturing as well as in retail and wholesale trade. Static factor analysis and a method building on canonical correlations are applied to construct a composite index of inventory fluctuations. Based on recursive estimates, the different variants are assessed as regards the stability of the weighting schemes and the ability to forecast the "true" inventory fluctuations better than the preliminary official releases.
\end{abstract}

JEL classification: E22, C32, C52.

Keywords: inventory investment, revisions, composite indices, canonical correlation, factor models, national accounts data, Ifo business survey, Germany.

\author{
Thomas A. Knetsch \\ Economics Department \\ Deutsche Bundesbank \\ Wilhelm-Epstein-Str. 14 \\ 60431 Frankfurt am Main \\ Germany \\ thomas.knetsch@bundesbank.de
}

The author would like to thank Erich Langmantel for a stimulating discussion as well as Jörg Breitung, Jörg Döpke, Hermann-Josef Hansen, Heinz Herrmann and the participants of the CESifo workshop for valuable comments and suggestions. Of course, the author is fully responsible for all remaining shortcomings. The paper expresses the author's personal opinion which does not necessarily reflect the views of the Deutsche Bundesbank. 


\section{Introduction}

Amongst business cycle analysts, the German national accounts statistics of inventory investment are regarded as being unreliable as far as preliminary data releases are concerned. However, especially around cyclical turning points, judgement on current and future trends in inventories often plays an important role in the diagnosis of recent economic developments as well as in short-term macroeconomic forecasting.

In fact, the pro-cyclical movement of inventory investment in business cycles is a result which is well established both in economic theory and in empirical studies. ${ }^{1}$ From the theoretical perspective, the key reference is still Metzler's [1941] inventory accelerator mechanism, which is based on the traditional production-smoothing/buffer-stock hypothesis of inventory behavior. $^{2}$ Empirical evidence proves the destabilizing effect of inventory investment on aggregate output. ${ }^{3}$ In applied business cycle research, inventory fluctuations are seen as being central to the explanation of minor business cycles. ${ }^{4}$ Furthermore, it is argued that destocking is an important phenomenon during recessions.

Against this background, it is surprising that the statistical basis for an analysis of inventory investment is extraordinarily weak in the German national accounts. Since the conversion to the European System of Accounts 1995 (ESA 95), the primary basis for the compilation of changes in inventories, i.e. annual data on inventory stocks in sectoral division, has no longer been published. In the preliminary releases of quarterly national accounts, inventory changes are (to a large extent) measured as a residual when reconciling the production and the expenditure concept of GDP. As a consequence of this approach, preliminary data on inventory investment are tremendously prone to revision and thus highly unreliable. ${ }^{5}$

It is therefore important to base the judgement on the current stance of the inventory cycle on alternative sources. On a monthly basis, the Ifo institute publishes survey data on the assessment of inventory stocks in

\footnotetext{
${ }^{1}$ Recent survey articles stressing this result are Ramey and West [1999] and Blinder and Maccini [1991].

${ }^{2}$ Since the early $1980 \mathrm{~s}$, the production-smoothing/buffer-stock hypothesis has been called in question. A strand of literature, perhaps initiated by Blinder [1981], argues in favor of the so-called $(\mathrm{S}, \mathrm{s})$ approach to inventory behavior which stresses the stock-out problem: whenever inventory stocks are expected to reach a critical lower margin s, firms are going to replenish stockholdings up to the upper limit S. On the micro level, the implications of this hypothesis are quite different.

${ }^{3}$ An early comprehensive study of the impact of inventory fluctuations on business cycle movements is Abramovitz [1950]. Apart from the above-cited references, detailed inquiries of inventory fluctuations are presented in Blinder and Holtz-Eakin [1986] for the United States as well as in Knetsch [2004] and Döpke and Langfeldt [1997] for Germany.

${ }^{4}$ See Zarnowitz [1985] and Moore and Zarnowitz [1986], for instance.

${ }^{5}$ Even for the United States where primary statistics of inventories are much more detailed, inventory investment figures are often revised substantially (see Howrey [1984]).
} 
manufacturing as well as in the retail and wholesale trade sector. Although the survey on manufacturers' inventories only captures stocks of finished goods, (virtually) all sectors holding significant proportions of inventories are considered in this data set. Furthermore, survey data is available in a timely manner and free of revisions.

However, in order to obtain an aggregate measure of inventory fluctuations, one has to address the issue of amalgamating information from different sources. In order to construct a composite index of inventory fluctuations, we will apply different methodologies. The composite index may be given by the codependent cycle of the three Ifo series at hand which is identified by analyzing canonical correlations. Alternatively, the common factor might be obtained by means of classical static factor analysis. In an investigation based on recursive estimates of the composite indices, the methods are compared with respect to the stability of the weighting schemes.

We will further show that, regardless of which composite index is considered, the use of Ifo survey data helps to explain the difference between the first and the "final" release of inventory investment in the national accounts statistics. Moreover, simple indicator-based forecasting models clearly outperform the first announcement of the Statistisches Bundesamt in predicting the "true" picture of the inventory fluctuations. Hence there might be an ongoing debate on the best way of extracting the common factor from the Ifo series. However, it turns out to be rather clear that, as regards the aggregate inventory fluctuations of the German economy, the Ifo business survey provides information which is most reliable in a real-time forecasting exercise.

The remainder of the paper is organized as follows. In Section 2, we first study the time series properties of our reference, the seasonally adjusted series of real inventory investment drawn from the German national accounts. We also illustrate to which extent this series has been revised in recent years. Then, we present time series characteristics of the three Ifo indicator series including a discussion on their comovement with the reference, both in the time and the frequency domain. In Section 3, we construct a composite index of inventory fluctuations by extracting the common factor from the Ifo series by means of canonical correlation and static factor analysis. In Section 4, an evaluation of the methods is presented which is based on recursive estimates. In this context, two criteria are of interest: the stability of the weighting schemes in the case of re-estimation with an updated data set and the predictive content for "true" inventory cycle movements. Finally, Section 5 concludes. 


\section{Time Series Properties of the Reference and the Ifo Indicator Series}

The first part of this section is devoted to a discussion of the seasonally and working-day adjusted time series properties of inventory investment in real terms as published in the national accounts. We will argue that the series shows cyclical features which are usually attributed to inventory fluctuations. Therefore, the national accounts data on inventory investment serve as our reference series in the sense that it generally approximates the inventory cycle of the German economy.

At the end of sample, however, the series is tremendously prone to revision. Hence, in order to assess the current stance of the inventory cycle or to forecast its prospective path, it is necessary to rely on different data sources. We will show that the inventory series published in the Ifo business survey are good candidates in this respect because they fulfill the important indicator property of a high correlation with the reference. In the second part of the section, this strong empirical connection is documented by using standard time series techniques.

\subsection{The Time Series of Inventory Investment}

Figure 1 shows the plot of the time series of inventory investment in the sample between the first quarter of 1970 and the second quarter of 2003. Whereas the data prior to 1991 refer to West Germany, the whole series is measured using the ESA 95 principles. ${ }^{6}$

Because of dominating erratic variations, ${ }^{7}$ it is convenient to filter the series using an optimal low-pass filter which passes only oscillations which are longer than $1 \frac{1}{2}$ years. ${ }^{8}$ Simply by counting the peaks and troughs of the filtered series, we observe eight full inventory cycles in 30 years which leads (in a purely arithmetical sense) to an average periodicity of $3 \frac{3}{4}$ years. In the traditional classification of cycle movements, such a duration fits to the

\footnotetext{
${ }^{6}$ In that respect, this paper differs from Knetsch [2004], in which the West German series measured according to the previous accounting standards has been chained up with the series for (unified) Germany measured according to the ESA 95 principles. In the series used here, there is only a statistical break owing to the unification but no longer a break owing to the change in the accounting standards at the same date. Further information on the statistical breaks during the 1990s is given in Appendix A.2.

${ }^{7}$ The erratic fluctuations are (to some extent) a result of the seasonal and calendar adjustment procedure applied: since the aggregates of the production and the expenditure side of GDP are separately adjusted for seasonal and calendar effects, statistical discrepancies are almost certain to arise. By convention, the remaining calendar effects are attributed to the series of inventory investment in order to meet the GDP accounting identity.

${ }^{8}$ The filter lag length is 4 . For the construction of this type of filter, see Baxter and King [1999], for instance.
} 
Figure 1: Series of inventory investment

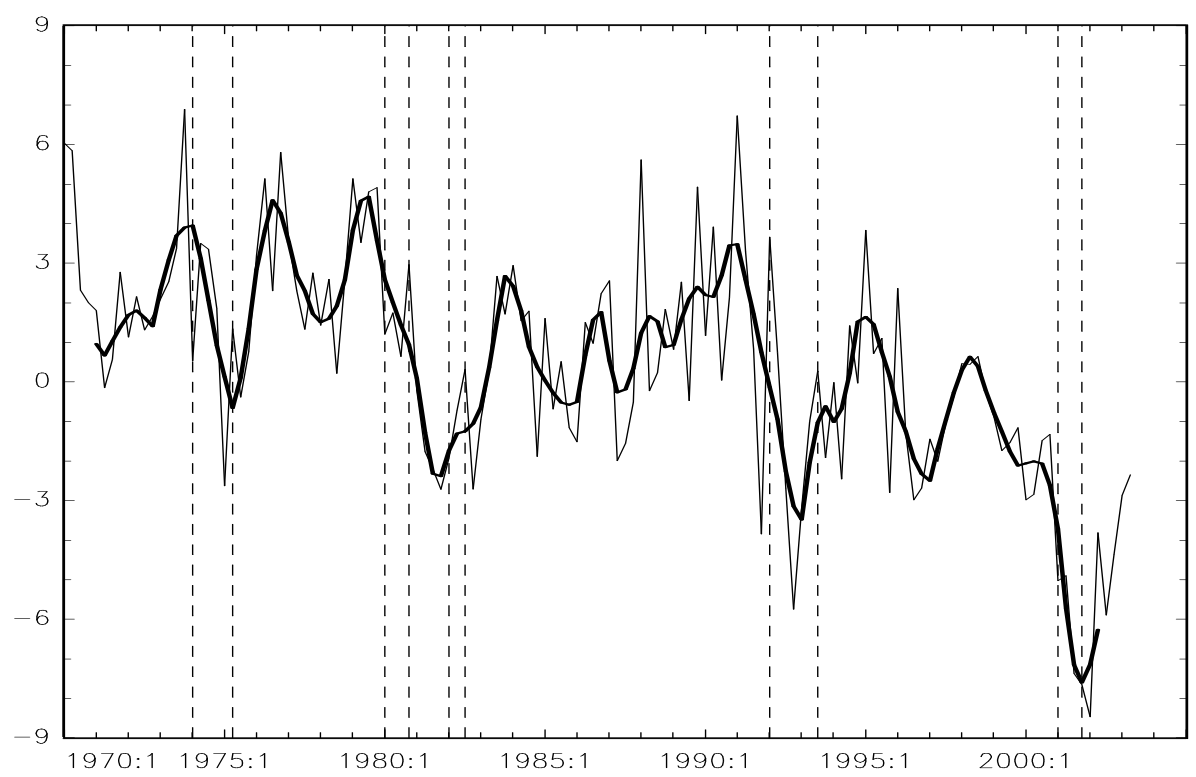

Inventory investment is seasonally and working-day adjusted and measured in billions of 1995 euro. Source: National accounts published in August 2003. The original series is plotted by the solid line and the filtered series by the thick line. Vertical lines indicate the beginning and the end of the recession periods (technically defined).

class of so-called "Kitchin cycles" (i.e. about three to four years) which are usually attributed to inventory fluctuations. ${ }^{9}$

Further important stylized facts concern the relationship of inventory changes to aggregate fluctuations. ${ }^{10}$ In macroeconomics, it is common knowledge that inventories are a destabilizing factor in business cycles. During recessions, we usually observe that firms reduce inventory stocks by a sizeable amount. A look at Figure 1 shows that there is strong destocking during all cyclical downturns in Germany since $1970 .{ }^{11}$

By visual evidence, we therefore conclude that the series of inventory investment as published in the national accounts shows features typically attributable to aggregate inventory behavior which is known from economic theory and which is supported by empirical results from countries (such as the United States) where the statistical basis for compiling the figures of

\footnotetext{
${ }^{9}$ The cycle classification is sketched in Moore and Zarnowitz [1986], for instance.

${ }^{10}$ For a closer look at the stylized facts of the German inventory cycle, see Knetsch [2004], for instance.

${ }^{11}$ For simplicity, recessions are dated using the mechanical rule that seasonally adjusted real GDP declines in at least two consecutive quarters.
} 
Figure 2: Data revisions with respect to inventory investment

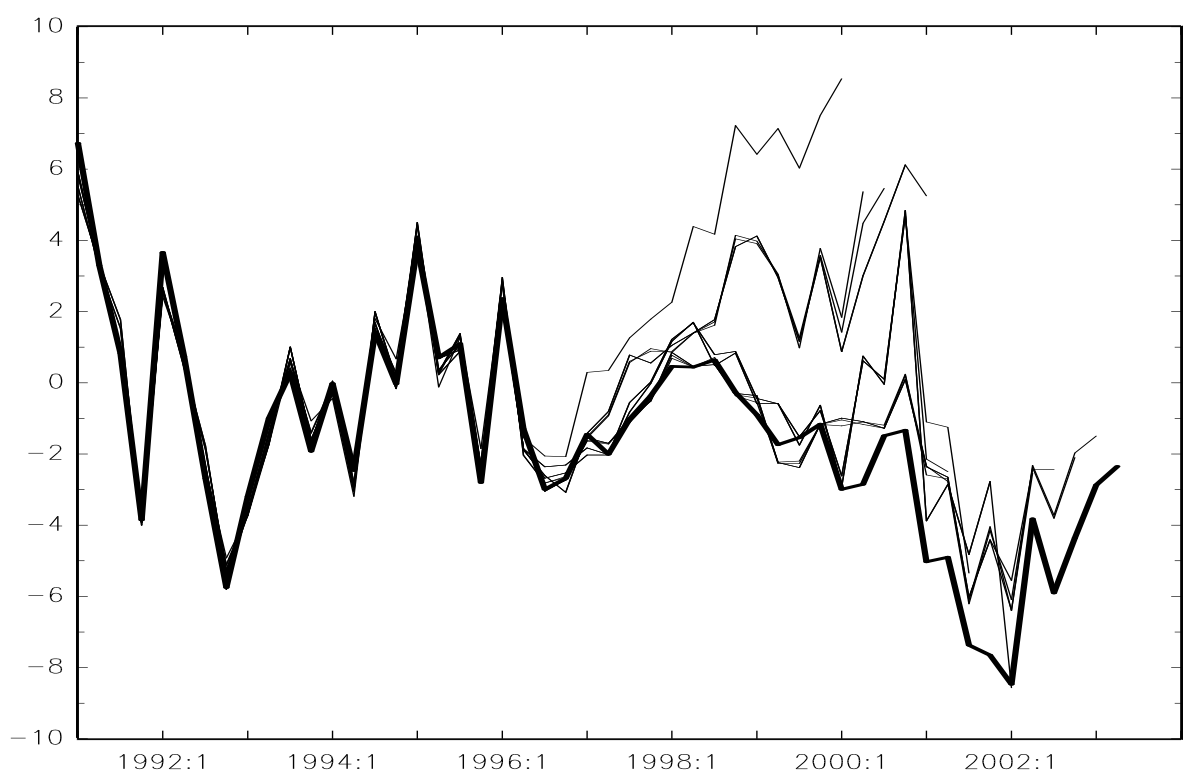

The last 14 releases of seasonally adjusted changes in inventories (in billions of 1995 euro) are plotted with regard to the publications of the national accounts from May 2000 through August 2003. The current release is plotted by the thick line.

inventory investment is less weak than in Germany. Although we claim that national accounts data on inventory investment are generally appropriate as a proxy of aggregate inventory behavior in a historical perspective, we will show right now that the use of those figures for the purpose of current business cycle diagnosis and short-term forecasting is rather dangerous.

Figure 2 highlights the fact that the data on inventory investment are very susceptible to revision. It is worth mentioning that those revisions are for the most part a consequence of the poor quality of the original data. ${ }^{12}$ The reasons for that are evident: As a product of the evaluation of the inquiries about the cost structures of firms, data on inventory stocks in sectoral division are only ascertained in annual periodicity and with a considerable time lag. ${ }^{13}$ Since the conversion to ESA 95, these data have no longer been published. In the preliminary releases of quarterly national accounts, however, inventory changes are (to a large extent) determined as a residual of GDP (measuring according to the production concept) and the

\footnotetext{
${ }^{12}$ Another source of revisions is the seasonal adjustment procedure. However, revisions induced by that are thought to be of limited extent compared to changes in raw data.

${ }^{13}$ For the compilation of inventory investment based on sectoral inventory stocks, see Statistisches Bundesamt [2003], pp.295-304.
} 
sum of the expenditure aggregates. ${ }^{14}$ Since these quantities are measured with uncertainty, preliminary figures of inventory investment also include statistical discrepancies. After two years or so, when detailed statistical information (such as the results of the value-added tax statistics and the inquiries about the cost structures of firms) had been incorporated into the system of national accounts, the inventory investment figures are more or less free of that kind of mismeasurement.

For the above-mentioned purposes, waiting for two years is not a feasible option. Hence, we search for other data sources which enable us to proxy the German inventory cycle with timeliness and reliability.

\subsection{The Ifo Indicator Series}

In its business survey, the Ifo institute asks the participating firms to assess inventory stocks. Firms in manufacturing as well as in the retail and wholesale trade sector are invited to give their view on whether inventories are regarded as being too small, sufficient/normal (in seasonal terms), or too big. The individual qualitative answers are aggregated by weighting the proportion of positive and negative replies. For interpretational reasons, the scale of the aggregates is inverted because an increasing proportion of firms reporting too small inventory stocks indicates a rising expansive pressure on upstream sectors in the value-added chain and vice versa. ${ }^{15}$ On a monthly basis, Ifo institute publishes indicators for manufacturers' assessment of inventory stocks of finished goods and for the assessments of stockholdings in retail and wholesale trade. Whereas the former indicator includes East German firms, the latter two only correspond to the West German trade sector.

To avoid problems which potentially arise from different scales, the three series used are standardized such that they possess zero means and unit variances. In Figure 3, the quarterly averages of the Ifo series are plotted in the sample between the first quarter of 1970 and the second quarter of $2003 .{ }^{16}$ In general, all series show a cyclical pattern, although it is not always clear-cut. Whereas the series of manufacturers' inventories is (surprisingly) smooth, depicting cycles of appropriate duration and clear turning points, the series of retail and wholesale traders' inventories are much more erratic. Apart from some short-term fluctuations, at least the series attached to wholesale trade is clearly oscillating at inventory cycle frequencies.

\footnotetext{
${ }^{14}$ As mentioned in Braakmann [2003], for the preparation of new quarterly figures, the Statistisches Bundesamt has recently started using the Ifo business survey on the assessment of inventory stocks to cross-check the general adequacy of the figure which comes out of the residual accounting and which is called inventory investment.

${ }^{15}$ Further details on the Ifo business survey are given in Oppenländer and Poser [1989].

${ }^{16}$ We plot the time series on the basis of quarterly averages for the sake of better visibility of (potential) cycling at business cycle frequencies.
} 
Figure 3: Ifo indicator plots

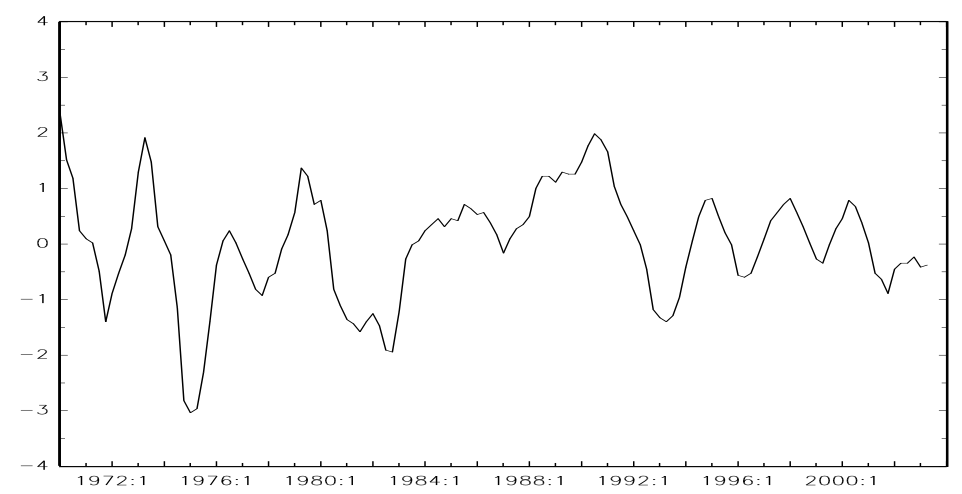

Figure 3: (a) Assessment of Manufacturers' Inventory Stocks

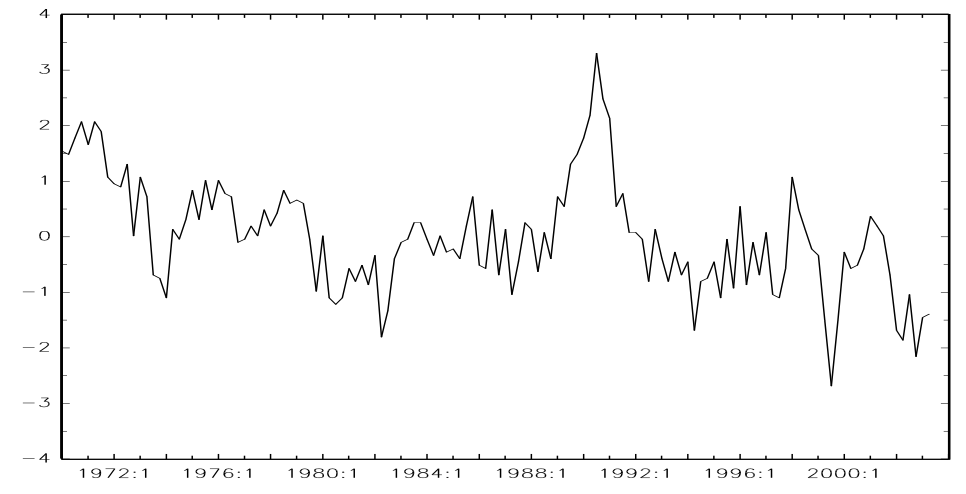

Figure 3: (b) Assessment of Retail Traders' Inventory Stocks

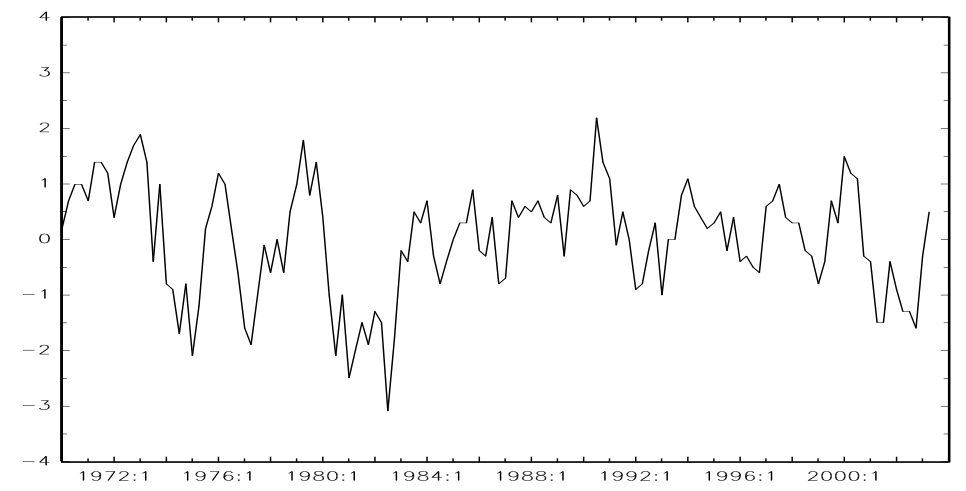

Figure 3: (c) Assessment of Wholesale Traders' Inventory Stocks

A positive value indicates that, in the aggregate, inventory stocks are regarded as being "favorable" which means that the proportion of "too big" judgements (relative to the sum of "too big" and "too small" answers) is below average. A negative value indicates an "unfavorable" stance in that sense. 
Table 1: Cross-correlation between indicators and inventory investment

\begin{tabular}{|c|c|c|c|c|c|c|c||}
\hline \multirow{2}{*}{ Indicator } & \multicolumn{3}{|c|}{ lag } & coin. & \multicolumn{3}{|c|}{ lead } \\
\cline { 2 - 8 } & -3 & -2 & -1 & 0 & +1 & +2 & +3 \\
\hline manufacturers' invent. & .06 & $.18^{(\star)}$ & $.28^{\star \star}$ &. $\mathbf{3 6}^{\star \star}$ & $.35^{\star \star}$ & $.23^{\star}$ & .09 \\
retail traders' invent. & $.24^{\star}$ & $.29^{\star \star}$ & $.28^{\star \star}$ & $.35^{\star \star}$ & $.33^{\star \star}$ & $.40^{\star \star}$ & $.31^{\star \star}$ \\
wholesale traders' invent. & -.03 & .06 & .16 & $.24^{\star}$ & $.31^{\star}$ &. $\mathbf{3 7}^{\star \star}$ & $.25^{\star}$ \\
\hline
\end{tabular}

Correlations between the indicators and the respective lead or lag of the series of inventory investment are reported. $\left.{ }^{\star \star},{ }^{\star},{ }^{(}\right)$means rejection of the null hypothesis of no cross-correlation at the $1 \%, 5 \%$ and $10 \%$ level respectively. Standard errors are calculated using Newey and West's [1994] heteroskedasticity and autocorrelation consistent covariance; lag truncation is 4 . The largest correlation is printed in bold.

It is interesting to have a look at the cross-correlations between the Ifo series and inventory investment for the following reasons. First, only if the Ifo series are correlated with the reference to a sufficiently large extent, can they serve as indicators for the inventory cycle. Second, in order to simplify the interpretation of the results of the statistical methodologies which will be applied in the subsequent section, it is worth knowing whether or not there are phase shifts between the series.

In Table 1, we report the estimates of cross-correlations between the Ifo series and inventory investment in the sample from the first quarter of 1970 through the final quarter of $2001 .^{17}$ Since the results show significant cross-correlations, an important indicator property is satisfied for all Ifo series. Whereas the series of manufacturers' inventory stock can be seen as a coincident indicator, the assessments of retail and wholesale traders turn out to lead the reference series. Albeit quite close to each other, the highest cross-correlation is found with the series of retail traders' inventories. At first glance, this result is puzzling because visual inspection would indicate that, just between these series, the extent of co-cycling is lowest. However, by fading out the enormous peak located around the unification, in the series of retail traders' inventory assessment, we observe a slightly negative trend which seems to inhere in the reference series as well. In other words, the estimated cross-correlation between the series of retail traders' assessment

\footnotetext{
${ }^{17}$ The final observations are dropped from the analysis for two reasons. First, we want to measure to which extent the Ifo series are correlated with the "true" inventory fluctuations, which means that only revised data should be used. Second, as already mentioned in footnote 14, the Statistisches Bundesamt uses information from the Ifo business survey in order to cross-check the preliminary figures of inventory investment. Hence, these figures may be (at least) partially affected by Ifo survey information. If we included preliminary figures of inventory investment, we would risk measuring artificial correlations.
} 
Figure 4: Spectra and coherences
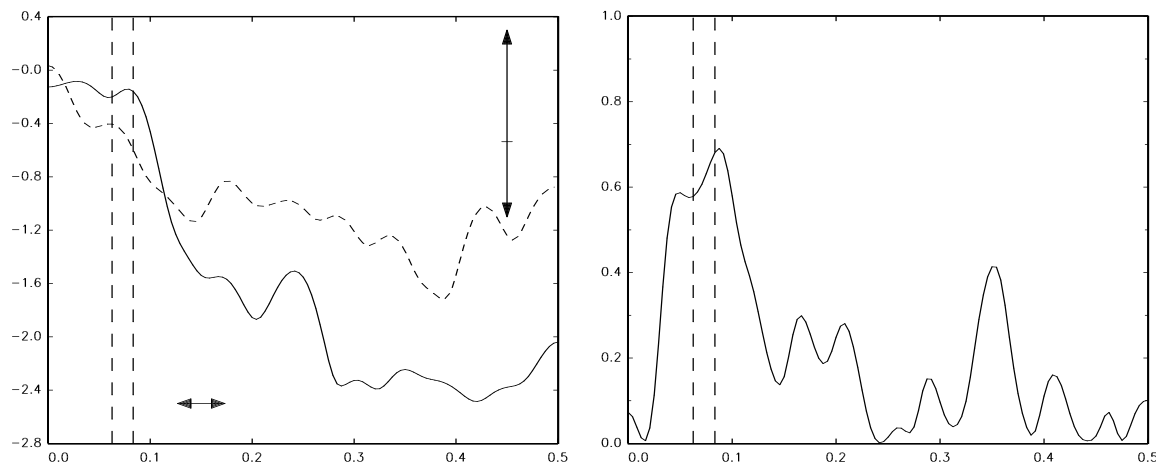

Figure 4: (a) Assessment of Manufacturers' Inventory Stocks
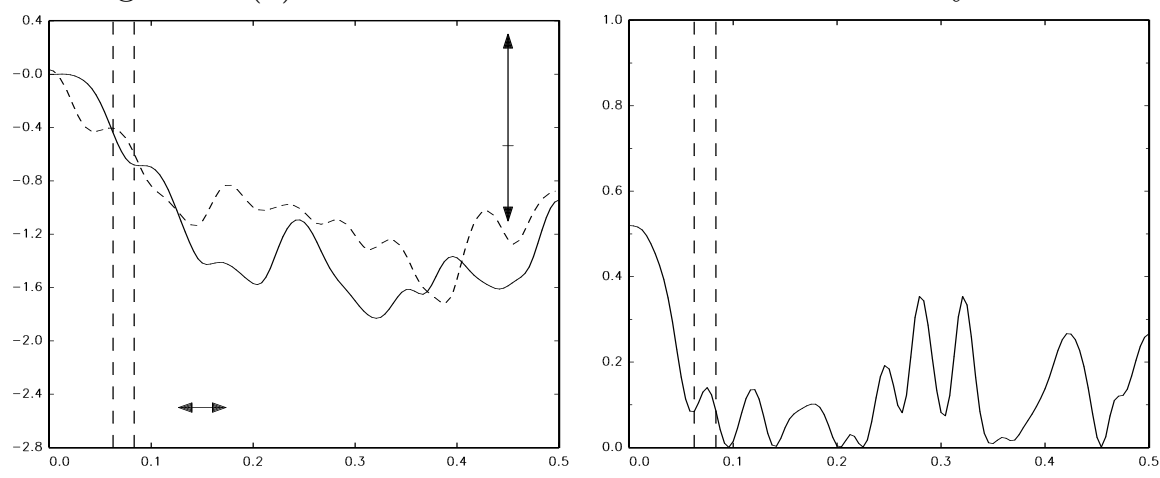

Figure 4: (b) Assessment of Retail Traders' Inventory Stocks
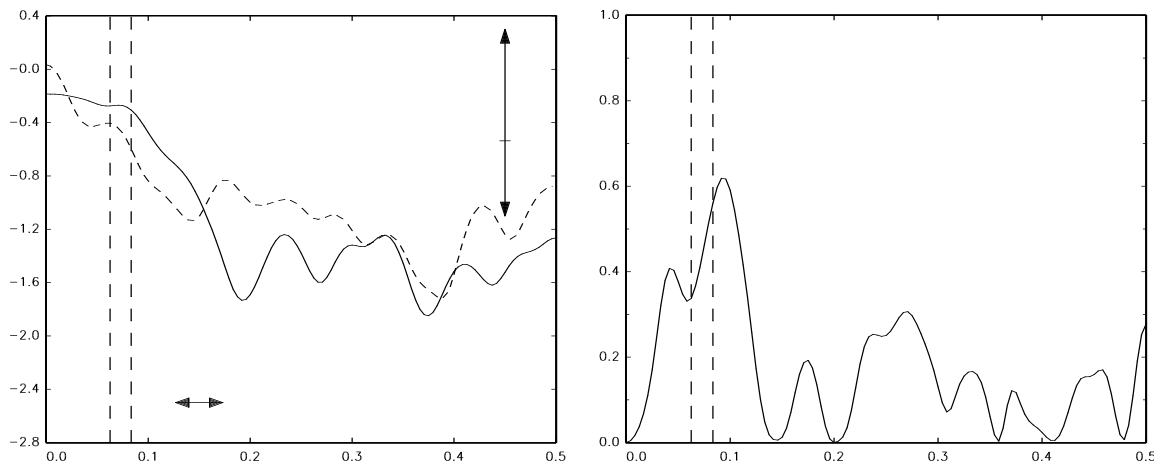

Figure 4: (c) Assessment of Wholesale Traders' Inventory Stocks

On the left-hand side, the graphs depict the log spectra of the respective Ifo series (solid line) and inventory investment (dashed line). On the right-hand side, the graphs show the coherence between those series. Spectra and cross-spectra are estimated using 128 data points and 40 covariances. The horizontal arrow depicts the bandwidth of the Parzen window used. The vertical arrow shows the asymptotical $90 \%$ confidence bands of the estimation of the log spectrum. The abscissa scale is frequency divided by $2 \pi$. The dashed vertical lines indicate frequencies attributed to periodicities of three and four years. 
and the reference might be a result of comovement at very low frequencies.

In Figure 4, the log spectra and coherences of the series are plotted. Inventory investment turns out to possess Granger's [1966] "typical spectral shape of an economic variable" rather than a clear peak at frequencies attributed to "Kitchin cycles". During the last three decades, firms have been able to reduce stockholdings owing to just-in-time production and improvements in information and communication technologies. These long-run effect does not seem to be of less importance than classical inventory cycle movements. Moreover, the convention of the seasonal and calendar adjustment procedure to assign residual calendar factors to changes in inventories may be responsible for considerable fluctuations in the very short run. ${ }^{18}$ Taking these effects together, we end up with an explanation for the flat decline of the log spectrum of inventory investment.

The Ifo series of retail and wholesale traders' assessments of inventory stocks virtually mimics the reference series in terms of spectral shape. If at all, significant differences turn out to exist between the reference and the Ifo series of manufacturers' assessment at high frequencies. ${ }^{19}$ However, the plots of the coherences between the Ifo series and the reference show more substantial results. For manufacturers' and wholesale traders' inventory assessments, the degree of linear association, as measured by its coherence, is largest at inventory cycle frequencies whereas it is negligible for retail traders' assessment. In the latter case, the absolute peak of the coherence is observed around the zero frequency.

In sum, the Ifo series under consideration may generally serve as indicators of inventory planning of German firms. Whereas the Ifo data of retailers' inventory assessment seem to replicate the general tendency to reduce stockholdings in the past decades, manufacturers' and wholesale traders' assessments show a large extent of co-cycling with the reference at frequencies which are typically attributed to inventory cycle movements. Hence, it is worth considering all indicators at hand because each of them provides specific information.

\section{Composite Indices of Inventory Fluctuations}

On a monthly basis, the Ifo business survey publishes three series which can generally serve as indicators of inventory fluctuations in Germany. Since several individual indicators may send different signals, one has to decide

\footnotetext{
${ }^{18}$ See also footnote 7 .

${ }^{19}$ Since spectra and coherences are intended to show details in the range of business cycle frequencies, a short bandwidth has been chosen. As a consequence, the uncertainty surrounding the estimation of the spectra is rather high. It is worth mentioning that the general characteristics of the spectral shapes remain unaffected if fewer covariances are used for the estimations.
} 
either to trust only one of them, say, manufacturers' assessment of inventories of finished goods, or to construct a composite index amalgamating the information provided by all indicators. In principle, the latter approach aims at extracting comovement of the indicator series at hand. ${ }^{20}$ In factor models which have recently become popular, comovement is represented by a (small) number of common factors. An alternative strategy is to identify so-called codependent cycles in a vector autoregressive model. This can be done by using canonical correlation analysis.

The composite indices which will be constructed on the basis of these two methodologies share the simple design. Namely, they can be explicitly or implicitly expressed as a weighted average of the Ifo series.

\subsection{Codependent Cycle Analysis}

The concept of codependent cycles was introduced by Vahid and Engle [1997] building on an earlier paper written by Gouriéroux and Peaucelle [1992]. Two stationary series bearing considerable serial correlation are said to possess a codependent cycle if there is a linear combination between the two which can be represented by a moving average of a very short order, say $q$ $[\mathrm{MA}(\mathrm{q})]$. From that definition, it is clear that codependence relations are unpredictable at horizons larger than $q$.

It is worth mentioning that the idea of codependent cycles generalizes Engle and Kozicki's [1993] concept of common cycles, which requires that the linear combination be white noise (or unpredictable at all horizons). Whereas co-cycling between the original series needs to be exactly synchronized in the case of common cycles, the more general concept allows for possible phase shifts. In recalling the results of the previous section, if at all, we should only succeed in identifying codependent cycles.

In a system of $K$ variables, there may exist up to $K-1$ independent codependence relations. Given an autoregressive model of order $p$ for the $K$-dimensional vector $x_{t}$, one can test for the number of codependence vectors using a statistic proposed by Tiao and Tsay [1989] which builds on a canonical correlation analysis between $x_{t}$ and $\left(x_{t-q-1}, \ldots, x_{t-q-1-p}\right)$. In fact, the number of zero canonical correlations determines the number of $\mathrm{MA}(q)$ codependence vectors. The test statistic for the null hypothesis that there are (at least) $s \operatorname{MA}(q)$ codependent vectors is given as follows:

$$
\mathrm{C}(s ; q)=-(T-p-q) \sum_{i=1}^{s} \ln \left(1-\lambda_{i}(q)\right)
$$

\footnotetext{
${ }^{20}$ In the present analysis, we only use the three Ifo series. The decision not to use a production-sales index is due to a conceptual change in the statistic of monthly industrial turnovers which disturbed the stable relation between production, turnovers, and producer prices documented in Knetsch [2004].
} 
Table 2: Tests for codependent cycles

\begin{tabular}{|c|c|cccc|}
\hline \# codep. & Degrees of & \multicolumn{4}{|c|}{ Order of moving average } \\
\cline { 3 - 6 } vectors & freedom & 0 & 1 & 2 & 3 \\
\hline 1 & 10 & $85.11^{\star \star}$ & $24.41^{\star \star}$ & $17.29^{(\star)}$ & 6.85 \\
2 & 22 & $229.95^{\star \star}$ & $74.80^{\star \star}$ & $47.26^{\star \star}$ & 27.73 \\
3 & 36 & $1083.36^{\star \star}$ & $179.91^{\star \star}$ & $103.23^{\star \star}$ & $64.93^{\star \star}$ \\
\hline
\end{tabular}

The null hypothesis is that the number of codependent vectors is equal to (or greater than) indicated. Test statistics are asymptotically $\chi^{2}$-distributed with the reported number of degrees of freedom. ${ }^{\star \star},{ }^{\star},{ }^{(\star)}$ mean rejection at the $1 \%, 5 \%$ and $10 \%$ level respectively.

where $T$ is the number of observations and $\lambda_{i}(q)$ the $i$ th smallest squared canonical correlation corrected for the sample autocorrelation of the canonical variates. ${ }^{21}$ Tiao and Tsay prove that $\mathrm{C}(s ; q)$ is asymptotically $\chi^{2}$ distributed with $s[K(p-1)+s]$ degrees of freedom.

In a three-dimensional vector autoregressive model comprising the Ifo series at hand, we need to find two independent linear combinations which are moving averages of order $q$ in order to conclude that there is a single codependent cycle which might be interpreted as the composite index of inventory fluctuations.

In the sample between January 1980 and June 2003, we carry out such a canonical correlation analysis in order to test for the number of codependent vectors between the Ifo series. As a prerequisite, we have to determine the lag order of the vector autoregressive model. We select $p=4$ which is indicated as the best choice according to Akaike's information criterion (AIC) ${ }^{22}$ Table 2 reports the results of the codependence tests. As expected, the existence of any common cycle is clearly rejected. Even codependence relations leading to moving averages of orders 1 or 2 are not found in the system. However, if we accept that the codependence relations are predictable up to three months, we will end up with a single codependent cycle.

Using Vahid and Engle's generalized method of moments technique, we estimate the following two codependence relations which are moving averages of order 3 (standard errors in parentheses):

$$
W I_{t}-\underset{(0.10)}{0.61} M I_{t} \quad \text { and } \quad R I_{t}-\underset{(0.13)}{0.61} M I_{t}
$$

where $M I_{t}, R I_{t}$, and $W I_{t}$ represent the Ifo series of manufacturers', retail and wholesale traders' assessment of inventory stocks respectively.

\footnotetext{
${ }^{21}$ See Tiao and Tsay [1989] or Vahid and Engle [1997] for detailed information on the test statistic.

${ }^{22}$ In order to allow for rich dynamics in general, we opt for the AIC which leads to a less parsimonious parametrization compared to other information criteria; see Lütkepohl [1993], Chapter 4, for instance.
} 
For our purposes, however, it is important to know the codependent cycle (or the common factor) of the three Ifo series which is annihilated by the codependence relations. Let us define the three-dimensional vector $x_{t} \equiv\left(W I_{t}, R I_{t}, M I_{t}\right)^{\prime}$ and collect the two codependence vectors in the $(3 \times 2)$ matrix $\gamma$ such that $u_{t} \equiv \gamma^{\prime} x_{t}$ are the codependence relations. Following the projection theorem, $x_{t}$ can be uniquely decomposed as the direct sum of its orthogonal projections onto $\gamma$ and $\gamma_{\perp}$ where the three-dimensional vector $\gamma_{\perp}$ is the orthogonal complement of $\gamma$ satisfying $\gamma_{\perp}^{\prime} \gamma=0$ :

$$
x_{t}=\gamma\left(\gamma^{\prime} \gamma\right)^{-1} \gamma^{\prime} x_{t}+\gamma_{\perp}\left(\gamma_{\perp}^{\prime} \gamma_{\perp}\right)^{-1} \gamma_{\perp}^{\prime} x_{t} .
$$

Let us define $C \equiv \gamma\left(\gamma^{\prime} \gamma\right)^{-1}, D \equiv \gamma_{\perp}\left(\gamma_{\perp}^{\prime} \gamma_{\perp}\right)^{-1}$. Then, equation (3) can be written as $x_{t}=C u_{t}+D \eta_{t}$ where $\eta_{t} \equiv \gamma_{\perp}^{\prime} x_{t}$ is a scalar process which comprises the whole forecasting content of $x_{t}$ at horizons larger than three months. ${ }^{23}$ Owing to this property, the scalar process $\eta_{t}$ is taken as an estimate of the common factor driving the three Ifo series. ${ }^{24}$ Note that $\eta_{t}$ is unique up to a scaling factor. Therefore, in order to fix the common factor estimate, it is natural to define it as a weighted average of the observable series.

Given the codependence relations in (2), we end up with the following estimate of the common factor serving as a composite index of inventory fluctuations based on the codependent cycle analysis:

$$
C I_{t}^{c}=0.28 W I_{t}+0.27 R I_{t}+0.45 M I_{t} .
$$

Manufacturers' assessment of inventory stocks is given the highest weight in the composite index although it is less than one-half. The trade sector as a whole accounts for 55 per cent of the composite index, with the information from retail and wholesale traders being given equal weights.

\subsection{Factor Model Approaches}

In order to reveal comovement in multivariate time series, factor models are widely applied. Each time series is partitioned into a common and an idiosyncratic component. Whereas the latter is specific to each series, the common component is a linear combination of a (small) number of common factors.

Static factor analysis imposes the following structure on the set of $K$ (mean-adjusted) variables stacked in the vector $x_{t}$ :

$$
x_{t}=B f_{t}+\varepsilon_{t}
$$

\footnotetext{
${ }^{23}$ Because of codependence, $u_{t}$ is not predictable at horizons larger than 3 , i.e. $E\left(u_{t} \mid \Omega_{t-i-1}\right)=0$ with $i \geq 3$, where the information set contains the complete history of the process $x_{t}$, i.e. $\Omega_{t} \equiv\left\{x_{t}, x_{t-1}, x_{t-2}, \ldots\right\}$. Consequently, $E\left(x_{t} \mid \Omega_{t-i-1}\right)=$ $D E\left(\eta_{t} \mid \Omega_{t-i-1}\right)$ with $i \geq 3$.

${ }^{24}$ Note that, in a canonical transformation, the common factor is mixed up with noise (see Peña and Box [1987]).
} 
where $f_{t}$ is the $r$-dimensional vector of (unobserved) factors with $r<K$, $B$ the $(K \times r)$ matrix of factor loadings, and $\varepsilon_{t}$ a $K$-dimensional error term which is assumed to be a multivariate white-noise process with zero mean and the diagonal covariance matrix $\Psi$. Furthermore, "classical" static factor models assume factors to be white noise with zero means and unit variances and to be uncorrelated with each other and with the error terms, i.e. $E\left(f_{t} f_{t}^{\prime}\right)=I_{r}$ and $E\left(f_{t} \varepsilon_{t}^{\prime}\right)=0$.

Of course, the assumptions that both the factors and the error terms are not allowed to be serially correlated are too restrictive in the present context. By Doz and Lenglart [1999], however, it is shown that a maximum likelihood estimation of equation (5) leads to consistent parameter estimates as long as $f_{t}$ and $\varepsilon_{t}$ are (weakly) stationary.

In this setup, it is also possible to test for the number of factors. A likelihood ratio (LR) test of the form $\operatorname{LR}(r)=-2\left[\hat{L}-\hat{L}_{0}(r)\right]$ is asymptotically $\chi^{2}$-distributed with $\frac{1}{2}\left[(K-r)^{2}-K-r\right]$ degrees of freedom where $\hat{L}$ and $\hat{L}_{0}(r)$ are the values of the log likelihood function under the unrestricted and the restricted model respectively.

Note that the number of degrees of freedom indicates the number of over-identifying restrictions in the factor structure. In the system of interest where the three Ifo series are driven by a single common factor, the model is exactly identified. ${ }^{25}$ Hence we are not able to test for the adequacy of the structure imposed in the present setup. However, since the codependent cycle analysis has shown evidence of a single common factor in the data, we estimate equation (5) for the three Ifo series under $r=1$ by maximum likelihood.

With $x_{t}$ defined as in the previous section, we obtain the following estimates of the factor loadings and the residual covariance matrix:

$$
\hat{B}=(0.71,0.57,0.86)^{\prime} \quad \text { and } \quad \hat{\Psi}=\operatorname{diag}(0.50,0.68,0.25) .
$$

An estimate of the unobservable factor $f_{t}$ is given by the least squares projection $E\left(f_{t} \mid x_{t}\right)=\Sigma^{-1} B^{\prime} x_{t}$ where $\Sigma$ is the covariance matrix of $x_{t}$. In the present case, $\Sigma^{-1} B^{\prime}$ is a three-dimensional (transposed) vector which, if appropriately normalized, can be interpreted as a weighting scheme.

A composite index of inventory fluctuations based on the maximum likelihood estimation of a static factor model is represented by the following equation:

$$
C I_{t}^{f}=0.25 W I_{t}+0.15 R I_{t}+0.60 M I_{t} .
$$

Here, manufacturers' assessment of inventory investment accounts for 60 per cent of the composite index. Compared to the weighting scheme derived from the codependent cycle analysis, the manufacturing sector is therefore

\footnotetext{
${ }^{25}$ With $K=3$ and $r=1$, the expression which determines the number of degrees of freedom is zero.
} 
much more important. With 25 per cent, the weight of wholesale traders' inventory assessment is only reduced a little. The contribution of retail trade, however, is clearly lower than in equation (4).

It is worth noting that, albeit consistent, the maximum likelihood estimation of equation (5) is not efficient when $f_{t}$ and $\varepsilon_{t}$ are serially correlated. Hence Doz and Lenglart [1999] propose taking those results only as a first guess. According to their approach, in a second step one should set up a model which explicitly takes into account the dynamics of common and idiosyncratic components.

Whereas, as a standard, the idiosyncratic components are allowed to follow an autoregressive process of order 1 , more effort is put on the search of a suitable approximation to the dynamic structure of the common factor. Since cycles are to be modelled, the characteristic roots of the autoregressive polynomial describing the dynamics of the common factor should be complex. Hence the lag order needs to be at least 2. In testing this property, however, we find that only an autoregressive process of order 5 provides the desired result.

Altogether, we set up the following system of equations:

$$
x_{t}=B^{*} f_{t}^{*}+\left[\begin{array}{l}
\varepsilon_{1 t}^{*} \\
\varepsilon_{2 t}^{*} \\
\varepsilon_{3 t}^{*}
\end{array}\right], \quad\left[\begin{array}{l}
\varepsilon_{1 t}^{*} \\
\varepsilon_{2 t}^{*} \\
\varepsilon_{3 t}^{*}
\end{array}\right]=\left[\begin{array}{ccc}
\rho_{1} & 0 & 0 \\
0 & \rho_{2} & 0 \\
0 & 0 & \rho_{3}
\end{array}\right]\left[\begin{array}{l}
\varepsilon_{1 t-1}^{*} \\
\varepsilon_{2 t-1}^{*} \\
\varepsilon_{3 t-1}^{*}
\end{array}\right]+\left[\begin{array}{l}
u_{1 t} \\
u_{2 t} \\
u_{3 t}
\end{array}\right]
$$

where the common factor is given by

$$
f_{t}^{*}=a_{1} f_{t-1}^{*}+a_{2} f_{t-2}^{*}+a_{3} f_{t-3}^{*}+a_{4} f_{t-4}^{*}+a_{5} f_{t-5}^{*}+v_{t}
$$

and $u_{1 t}, u_{2 t}, u_{3 t}$, and $v_{t}$ are white noise processes which are independent of one another.

Written in state-space form, this model can be estimated by the Kalman filter. Note that the model is identified up to a scaling factor. By analogy to Doz and Lenglart, we decide to fix the variance of $v_{t}$. In fact, we (arbitrarily) set it equal to 0.01. Moreover, we impose zero restrictions on the parameters whenever possible.

The estimates show the following results. First, the vector of factor loadings is given by $B^{*}=(0.85,0.69,1.26)^{\prime}$ and the dynamic structure of the common factor is described as follows (standard errors in parentheses):

$$
f_{t}^{*}=\underset{(0.02)}{1.14} f_{t-1}^{*}-\underset{(0.02)}{0.18} f_{t-5}^{*}+v_{t} .
$$

Albeit close to a unit root process, the common factor turns out to be stable inducing oscillations with a duration of roughly four years. ${ }^{26}$ Hence shocks to the common factor are highly persistent.

\footnotetext{
${ }^{26} \mathrm{It}$ is difficult to test for the presence of a unit root in the common factor. Hence we follow an indirect argumentation: As documented in Appendix A.1, unit root tests indicate that the original series are stationary. Consequently, if the idiosyncratic components are stationary which is given by assumption, the common factor cannot possess a unit root.
} 
Second, whereas $\varepsilon_{1 t}^{*}$ and $\varepsilon_{2 t}^{*}$ (i.e. the idiosyncratic components of wholesale and retail traders' inventory assessment) possess significant autocorrelation, $\varepsilon_{3 t}^{*}$ turns out to be white noise. The variances of the idiosyncratic components, however, are estimated as $\operatorname{var}\left(\varepsilon_{1 t}^{*}\right)=0.60, \operatorname{var}\left(\varepsilon_{2 t}^{*}\right)=0.82$ and $\operatorname{var}\left(\varepsilon_{3 t}^{*}\right)=0.01$ which indicates a trivial factor structure: Apart from a small difference in the degree of smoothness, the series of manufacturers' inventory assessment determines the common factor $f_{t}^{*},{ }^{27}$ whereas the two inventory series of the trade sector are dominated by their idiosyncratic components.

Consequently, if the dynamic factor structure of equations (8) and (9) is imposed, the "composite" index of inventory fluctuations can be approximated by manufacturers' assessment of inventory stocks.

\section{Evaluation of the Methods}

The composite indices of inventory fluctuations proposed in the previous section will be evaluated with respect to two properties which, from our point of view, need to be fulfilled by a good composite index. First, its weighting scheme should be sufficiently stable when estimations are updated using newly entered data. Second, the composite index should possess forecasting power for the reference series. Note that the reference is not the first inventory investment figure reported by the Statistisches Bundesamt. Instead, it is the set of "final" releases as published in the national accounts. In other words, we are in search of an indicator which is able to diagnose the "true" inventory fluctuations in Germany better than the preliminary releases of the official statistics.

Additional to the variants resulting from the statistical methodologies used, we also include the unweighted average of the Ifo series in the investigation of forecasting performance. Of course, the unweighted average is the simplest composite index. By comparing its forecasting performance with that of the method-based variants, we are able to check whether the application of the statistical procedures creates any benefit.

The total number of observations used for the subsequent analysis is identical to that of the previous section, i.e. from January 1980 through June 2003. We will evaluate the composite indices which are recursively estimated starting with the first quarter of $1992 .{ }^{28}$ It is worth mentioning that the test and estimation procedures are carried out for March, June, September and December of the respective years because we need real-time estimates of the composite indices only quarterly.

In the first part, we will investigate the stability of the weighting schemes

\footnotetext{
${ }^{27}$ In fact, the correlation between the series of manufacturers' inventory assessment and the smoothed estimate of the state $f_{t}^{*}$ is virtually perfect.

${ }^{28}$ This date is chosen for reasons which are linked to the availability of real-time data of inventory investment and GDP.
} 
Figure 5: Recursive multivariate analysis of indicator series

(a) Lag order selection

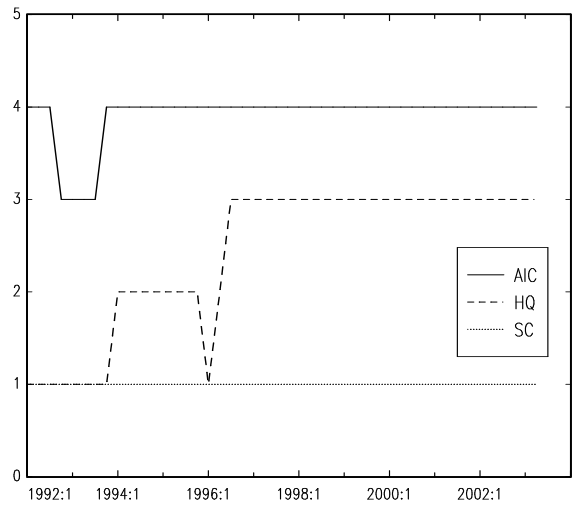

(b) Tests for codependence

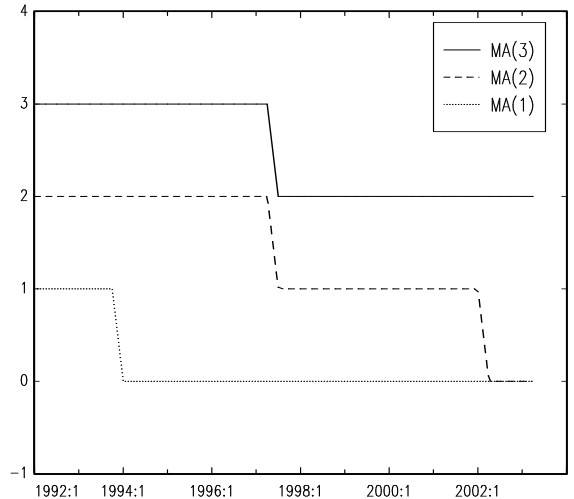

which are obtained applying codependent cycle and static factor analysis. In the second part, we will test whether or not the composite indices are able to predict the revisions of inventory investment. Furthermore, we attempt to find indicator-based forecasting models which outperform the first release published in the national accounts.

\subsection{Stability of the Weighting Schemes}

Equations (4) and (7) show the weighting schemes of the composite indices which are based on the codependent cycle and the static factor analysis respectively. In contrast, the Kalman filter technique does not provide an explicit weighting scheme. However, from an inspection of the properties of the resulting common and the idiosyncratic components, it is clear that the total weight is put on manufacturers' assessment of inventories. When the endpoint of the sample is varied, it turns out that this pattern does not change. For the "composite" index based on the Kalman filter technique, the property of stability is therefore fulfilled in a trivial manner.

Whereas the maximum likelihood estimation of the static factor model is carried out in a single step, the codependent cycle analysis is a sequence of specification tests and estimation procedures. Hence, it is not a priori clear whether the lag order of the underlying vector autoregression and the moving-average order of the codependence relations are the same for all samples under investigation.

Starting with the first quarter of 1992, the codependent cycle analysis is carried out quarter for quarter until the end of sample. ${ }^{29}$ Figure 5(a) shows the lag orders chosen by the AIC, the Hannan-Quinn (HQ) and the

\footnotetext{
${ }^{29}$ In each recursion, the begin of the sample is fixed to January 1980, whereas the end of the sample moves from March 1992 to June 2003.
} 
Figure 6: Recursive estimation of codependence vectors

(a) First codependence vector

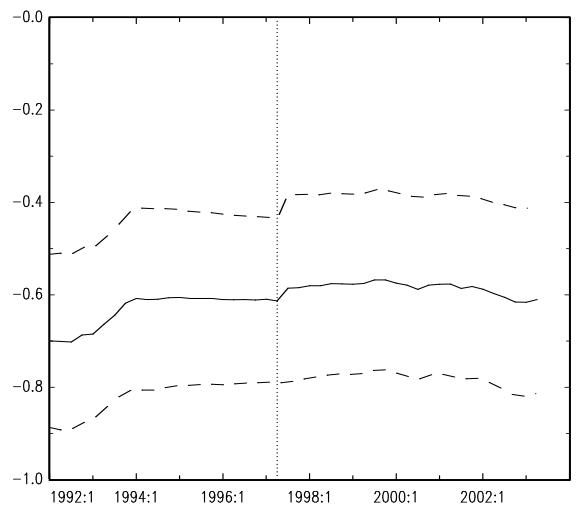

(b) Second codependence vector

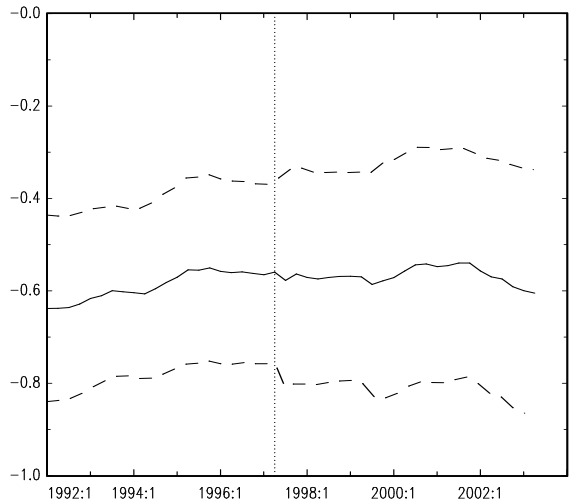

The graph on the left-hand side shows the recursive estimate of the coefficient attached to manufacturers' inventory assessment in its codependence relation with wholesale traders' inventory assessment. The graph on the right-hand side shows the respective estimates with respect to retail traders' inventory assessment. Note that the identification scheme is the same as in equation (2). Confidence bands of plus/minus two standard errors are given by the dashed lines. The vertical line indicates the structural change with respect to the moving average structure.

Schwarz criterion (SC). ${ }^{30}$ Except for a short period in 1992/93, the AIC criterion always selects lag order 4 . For simplicity, we therefore decide to set up vector autoregressions of order 4 .

Figure 5(b) depicts the test results for the number of codependence relations. Until the second quarter of 1997, we only need to allow for predictability up to order 2 in order to find the desired number of two codependence relations. For the remaining periods, however, two codependence relations which are moving averages of order 3 are identified. Since parameter estimation should be as efficient as possible, this structural change is taken into account.

Figure 6 shows the recursive estimates of the free parameters in the codependence relations. Perhaps with the exception of the first two or three years, the estimates are quite stable; both seem to be around -0.6. Furthermore, the estimates are significantly different from zero. Whereas the structural change in mid-1997 turns out to have a negligible impact on the parameter estimates, the confidence bands are a little bit wider in the scenarios where the codependence relations are moving averages of higher order.

Figure 7(a) shows the weights in the composite index which result from

\footnotetext{
${ }^{30}$ See, for instance, Lütkepohl [1993], Chapter 4, for an overview of lag order selection in vector autoregressions by means of information criteria.
} 
Figure 7: Recursive weights of Ifo series in the composite index

(a) Codependent cycle model

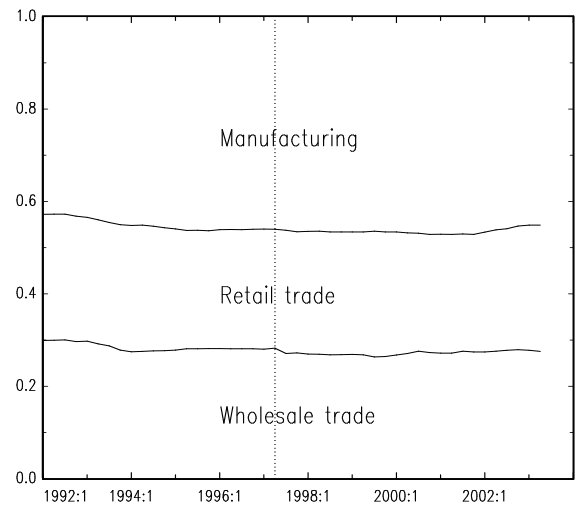

(b) Static factor model

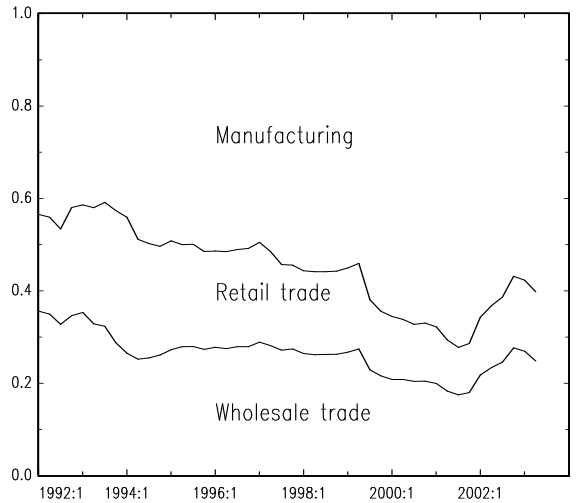

the recursive codependent cycle analysis. The weights are stable which is, of course, a consequence of the stable estimates of the codependence vectors. Over the whole period of interest, manufacturers' assessment of inventories contributes to little more than 40 per cent of the composite index, whereas the remaining share is divided into more or less equal contributions of retail and wholesale traders' assessments.

As a comparison, Figure 7(b) plots the weights which are obtained from recursive maximum likelihood estimation of the static factor model. In the first two years, the weighting schemes of both composite indices are quite similar. In the composite index based on the static factor model, however, the weight of the manufacturing sector increases from 1994 onwards. This is mainly due to a reduction of the weight of the retail sector. With almost 70 per cent, the contribution of manufacturers' inventory assessment reaches its peak in the second quarter of 2001. Since then, the weighting scheme is corrected back to the weighting scheme known from the codependent cycle analysis.

It is worth stressing that, relative to the results of the static factor model, the weights generated by the codependent cycle analysis show remarkable stability. This result might be explained by the fact that the codependent cycle analysis uses more information on the dynamics of the Ifo series than the static factor model. More precisely, imposing an appropriate vector autoregressive structure together with the form of (non-synchronized) co-cycling obviously helps to find a common factor which turns out to be rather insensitive to changes in the samples used for estimation. In terms of stability, we therefore conclude that the composite index based on the codependent cycle analysis is preferable to the alternative obtained from static factor analysis. 


\subsection{Predictive Content for Inventory Investment}

In Section 2.1, we argued that the series of inventory investment as published in the national accounts will be a good proxy for aggregate inventory fluctuations if, after at least two years, the statistical basis is comprehensive and detailed enough to compile reliable figures for GDP and the expenditure aggregates. In later revisions, unless conceptual modifications are introduced, the figures of inventory investment only change marginally. In this sense, they can be regarded as "final" releases which are taken as a reference in the subsequent analysis.

If the "true" picture is only available after two (or more) years, preliminary publications of the national accounts can be interpreted as forecasts. By taking them for granted (which is the conventional standard), it is implicity assumed that they are the best predictions available. This is probably the case for GDP and most of the expenditure aggregates. With respect to inventory investment, however, this implicit assumption can be called into question.

We will first have a look at the revision process. Specifically, we will ask whether there are predictable patterns in the difference between the "final" and the first release, and more precisely, whether the proposed indices help to predict the revision process. But even if this is the case, it is not yet clear how to use those indices in order to obtain better predictors for the "true" inventory fluctuations than the first release of the national accounts. In the second step, we will therefore set up simple indicator-based forecasting models and ask whether these estimates outperform the first publication of the Statistisches Bundesamt (taken as a predictor of the "final" release).

During the 1990s, German national accounts data undergo several important statistical breaks. The first is due to unification, the second due to the adoption of the ESA 95 accounting principles. In Appendix A.2, more information on this issue is presented. As a result, we base the subsequent analysis on inventory investment as a percentage of GDP in order to ensure the comparability between the first and the "final" releases. The sample used starts in the first quarter of 1992 and ends in the fourth quarter of $2001 .^{31}$

For our purposes, it is not necessary to examine the full revision process which takes into account all vintages. We only look at the first (or preliminary) release $p_{t}$ vis-à-vis the "final" release $y_{t}$ which is taken as the "true" picture of inventory investment as a percentage of GDP. In Figure 8, the first and the "final" release of the inventory-investment-to-GDP ratio are plotted. From visual inspection, it is obvious that, during the revision process, the variability is reduced significantly. ${ }^{32}$ In general, this is an indication

\footnotetext{
${ }^{31}$ As before, the last observations available are dropped from the analysis because they cannot be regarded as "final" releases.

${ }^{32}$ In the sample from the first quarter of 1992 to the fourth quarter of 2001, the standard
} 
Figure 8: Different releases of the inventory-investment-to-GDP ratio

(a) First release

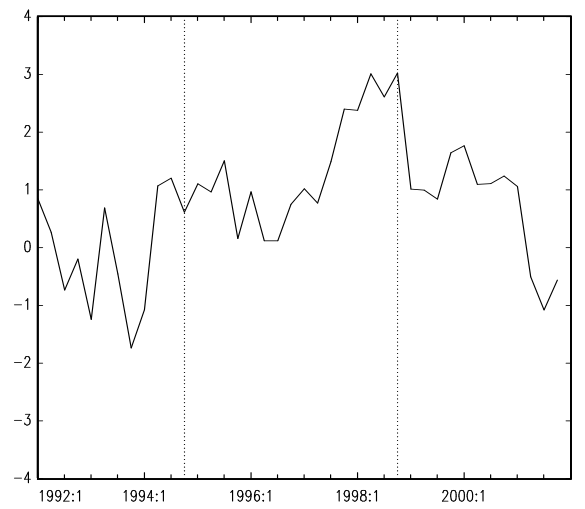

(b) "Final" release

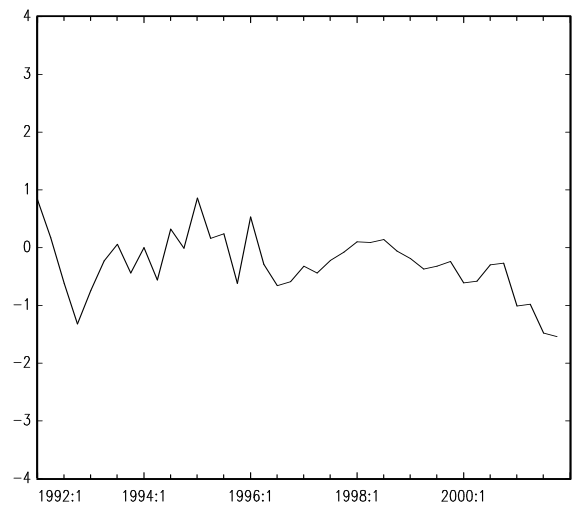

In the graphs, the inventory-investment-to-GDP ratios are plotted. The scale on the vertical axis is in per cent. In the left-hand graph, vertical lines indicate the dates of statistical breaks.

that the first announcements are measured with a considerable amount of error.

According to Mankiw, Runkle and Shapiro [1984] as well as Mankiw and Shapiro [1986], at the extremes, the revision process can be regarded as reducing measurement errors ("noise") or as incorporating new information ("news"). In the former case, the preliminary announcements should be an unbiased forecast of the "final" figures. In the latter case, however, the revision process should be uncorrelated with all information available at the time when the preliminary figures are compiled. By treating this compilation as a forecasting exercise, the latter hypothesis implies that the preliminary release is a rational prediction of the "final" figure.

In terms of Swanson, Ghysels and Callan [1999], a revision process is called inefficient if there is any predictable pattern. Apart from unbiasedness and orthogonality to available information, the difference between the "final" and the first release, denoted by $e_{t}$, needs to be free of autocorrelation. Hence, with $\epsilon_{t}$ defined as a zero-mean white-noise process, in the equation

$$
e_{t}=\text { const. }+\sum_{i=1}^{m} \theta_{i} e_{t-i}+\omega \operatorname{index}_{t}+\epsilon_{t},
$$

we ask whether there are any parameters which are different from zero.

Table 3 reports the regression results of different specifications of equation (11). Variant (A) simply tests whether the preliminary release is an

deviation of the time series of first releases of the inventory-investment-to-GDP ratio is 1.13 percentage points whereas it is 0.56 percentage points in the case of the final releases. 
Table 3: Modeling the revision process

\begin{tabular}{|c|c|c|cccc||}
\hline \hline $\begin{array}{c}\text { Dep. Var. } \\
\text { Sample }\end{array}$ & \multicolumn{7}{|l|}{$e_{t}$} & \multicolumn{6}{|c||}{} \\
\hline \hline Variant & $(\mathrm{A})$ & $(\mathrm{B})$ & \multicolumn{5}{|c|}{$(\mathrm{C})$} \\
\hline Index & & & $C I_{t}^{c}$ & $C I_{t}^{f}$ & $M I_{t}$ & $A V_{t}$ \\
\hline \hline const. & 1.13 & 0.24 & 0.48 & 0.44 & 0.45 & 0.47 \\
& $(0.17)$ & $(0.21)$ & $(0.19)$ & $(0.19)$ & $(0.18)$ & $(0.19)$ \\
$e_{t-1}$ & & 0.50 & 0.27 & 0.29 & 0.27 & 0.29 \\
& & $(0.14)$ & $(0.13)$ & $(0.13)$ & $(0.13)$ & $(0.13)$ \\
$e_{t-4}$ & & 0.30 & 0.44 & 0.41 & 0.38 & 0.45 \\
index $_{t}$ & & $(0.13)$ & $(0.12)$ & $(0.12)$ & $(0.11)$ & $(0.12)$ \\
& & & 1.09 & 0.99 & 0.73 & 1.11 \\
$\mathrm{R}^{2}$ & 0.00 & 0.47 & 0.63 & 0.62 & 0.64 & 0.61 \\
$\mathrm{AIC}$ & 2.89 & 2.35 & 2.05 & 2.08 & 2.02 & 2.10 \\
$\mathrm{SC}$ & 2.93 & 2.49 & 2.23 & 2.26 & 2.20 & 2.28 \\
$\mathrm{DW}$ & 0.67 & 1.75 & 1.93 & 1.91 & 1.94 & 1.93 \\
$\mathrm{LM}(4)$ & $6.09^{\star \star}$ & 0.26 & 1.17 & 1.02 & 0.92 & 1.19 \\
& {$[0.001]$} & {$[0.899]$} & {$[0.347]$} & {$[0.416]$} & {$[0.464]$} & {$[0.337]$} \\
\hline
\end{tabular}

The difference between the "final" and the preliminary release of inventory investment is denoted by $e_{t}$. Standard errors of the parameter estimates are given in parentheses. $\mathrm{R}^{2}$ is the determination coefficient, AIC is Akaike's and SC Schwarz's information criterion, DW is the Durbin-Watson statistic, and $\operatorname{LM}(4)$ is the $F$-statistic of the Breusch-Godfrey LM test for serial autocorrelation of order $4 ; p$-values are given in brackets. ${ }^{\star \star},{ }^{\star},{ }^{\star}{ }^{\star}$ mean rejection of the null hypothesis at the $1 \%, 5 \%$ and $10 \%$ level respectively.

unbiased predictor of the "final" release. Hence the first conclusion is that even the minimum requirement of unbiasedness is not fulfilled in this context. However, the Durbin-Watson and the Breusch-Godfrey statistics indicate that the residual process is not free of autocorrelation. In variant (B), we therefore use lags of $e_{t}$ as additional regressors. Apart from the first lag, we also need to include the fourth lag in order to obtain a white-noise residual sequence.

As argued in Section 2.1, preliminary data on inventory investment are to a large extent the result of a matching process between the production and expenditure accounts of GDP. Thereby, the aggregates are compiled by extrapolation based on the respective values of the year before. Additionally, these results are checked in terms of whether the seasonally adjusted figures implied also create a "sensible" picture. In some sense, both the first and the fourth lag are reference points in the process of compilation of national accounts. These procedural peculiarities may be responsible for the abovementioned empirical result.

The variants $(\mathrm{C})$ contain the full set of regressors as described in equa- 
tion (11). Apart from the method-based composite indices, we also present the regression result where index $x_{t}$ is given by the unweighted average of the Ifo series, denoted by $A V_{t}$. For either choice, we find that the composite index of inventory fluctuations helps to predict the revision process of the series of interest.

From a forecaster's perspective, however, this result is not fully satisfying because we do not yet have an indicator-based forecasting model which outperforms the first reported national accounts figure. In other words, we need to find a function $\xi_{t}=f\left(\right.$ index $\left._{t}\right)$ where $\xi_{t}$ is a predictor of $y_{t}$ based on the composite index. For simplicity, we choose the linear form

$$
\xi_{t}=\delta_{0}+\delta_{1} \text { index }_{t}
$$

where the coefficients $\delta_{0}$ and $\delta_{1}$ are the least squares estimates of an auxiliary regression of $y_{t}$ on the composite index and a constant.

In the subsequent evaluation, the predictions $\xi_{t}$ are recursive out-ofsample forecasts. For the auxiliary regressions, we actually need to have the complete set of data vintages of inventory investment and GDP for all forecasting dates, i.e. the first quarter of 1992 through the fourth quarter of 2001, and each vintage has to start in the first quarter of 1980. Such a data set is not available. However, since solely data which are regarded as "final" should be included in the auxiliary regressions, we are able to mimic the real-time forecasting exercise as follows. The August 2003 release of the inventory-investment-to-GDP ratio is used as the "final" release for all forecasting dates. However, the auxiliary regression is run over a sample which always starts in the first quarter of 1980 but which ends two years before the respective forecasting date. ${ }^{33}$

In Table 4, basic measures of forecasting accuracy are reported for the preliminary release $p_{t}$ as well as for the outcomes of the indicator-based forecasting models. The results of the first column once again highlight the extremely weak performance of the first publication of the national accounts in predicting the "true" ratio of inventory investment and GDP. In the sample used, the mean error is about one percentage point, which is enormous given that the quarterly inventory-investment-to-GDP ratio in absolute terms, averaged over the last three decades, is 0.7 per cent. In fact, the bias contributes to more than 50 per cent of the mean squared error between first and "final" release.

As Table 4 further shows, in terms of the mean absolute error and the root mean squared error, the indicator-based forecasting models clearly outperform the first official publication. However, with mean errors of 0.45

\footnotetext{
${ }^{33}$ By doing so, we implicitly assume that the figures which are regarded as "final" at the respective forecasting dates are identical to the August 2003 release of national accounts. Especially for inventory investment, this assumption is certainly not correct. However, the error appears to be limited.
} 
Table 4: Forecast evaluation

\begin{tabular}{|c|c|cccc||}
\hline \multirow{2}{*}{} & \multicolumn{5}{|c|}{ Predictor } \\
\cline { 2 - 6 } & $p_{t}$ & $f\left(C I_{t}^{c}\right)$ & $f\left(C I_{t}^{f}\right)$ & $f\left(M I_{t}\right)$ & $f\left(A V_{t}\right)$ \\
\hline \hline ME & -1.05 & -0.45 & -0.45 & -0.44 & -0.45 \\
MAE & 1.22 & 0.60 & 0.61 & 0.65 & 0.59 \\
RMSE & 1.44 & 0.75 & 0.76 & 0.78 & 0.73 \\
\hline Bias & 0.53 & 0.36 & 0.36 & 0.31 & 0.37 \\
Var. & 0.16 & 0.15 & 0.16 & 0.11 & 0.16 \\
Cov. & 0.31 & 0.49 & 0.48 & 0.58 & 0.47 \\
\hline
\end{tabular}

The preliminary release of the inventory-investment-to-GDP ratio is denoted by $p_{t}$, whereas $f(\cdot)$ denotes the forecasting model based on the respective composite index. ME is the mean error, MAE the mean absolute error, and RMSE the root mean squared error of the respective forecast. In the lower part of the table, the decomposition of the mean squared error of a forecast in its bias, variance and covariance contribution is presented.

percentage points (in absolute terms), the bias of these forecasts remains considerable. By comparing the results of the indicator-based forecasting models with one another, we find that the unweighted average performs best in the period under investigation. It is worth stressing that these differences are far from being statistically significant. ${ }^{34}$ Hence, while it is totally misleading to derive any ranking between the indicator-based forecasting models, we can conclude that the statistical procedures applied do not provide a weighting scheme for the composite index which outperforms a simple unweighted average of the Ifo series.

Table 5 reports formal tests for equal predictive ability and forecast encompassing. Since the difference between the indicator-based forecasting models are very small in terms of root mean squared errors, we do not test these models against one another. The Diebold-Mariano tests show that the reductions of mean squared errors implied by the indicator approach vis-à-vis the first publication of the national accounts are highly significant for all variants. Moreover, it comes as no surprise that, conditional on the information of the Ifo business survey, the first announcement of the Statistisches Bundesamt is not an efficient forecast of the "final" figure.

More interesting, however, are the results as regards the question whether or not the indicator-based forecasts encompass the information which is contained in the first publication of the national accounts. As reported in

\footnotetext{
${ }^{34}$ According to Ashley's [2003] simulation results, in the case of about 40 observations and substantially cross-correlated but only modestly autocorrelated forecast errors (which can be assumed in the present case), a $25 \%$ to $35 \%$ reduction in mean squared error is necessary to obtain a result which is statistically significant at the $5 \%$ level.
} 
Table 5: Forecast accuracy tests

\begin{tabular}{|c|c|c|c|c|}
\hline & \multicolumn{4}{|c|}{ Predictor: $\xi_{t}=$} \\
\hline & $f\left(C I_{t}^{c}\right)$ & $f\left(C I_{t}^{f}\right)$ & $f\left(M I_{t}\right)$ & $f\left(A V_{t}\right)$ \\
\hline mod. Diebold-Mariano & & & & \\
\hline $\mathrm{H}_{0}: \xi_{t} \sim p_{t}$ & $\begin{array}{l}3.60^{\star \star} \\
{[0.001]}\end{array}$ & $\begin{array}{l}3.55^{\star \star} \\
{[0.001]}\end{array}$ & $\begin{array}{l}3.44^{\star \star} \\
{[0.001]}\end{array}$ & $\begin{array}{l}3.65^{\star \star} \\
{[0.001]}\end{array}$ \\
\hline Forecast encompassing & & & & \\
\hline $\mathrm{H}_{0}: p_{t} \mathrm{CE}\left(\xi_{t}\right)$ & $\begin{array}{l}3.67^{\star \star} \\
{[0.000]}\end{array}$ & $\begin{array}{l}3.65^{\star \star} \\
{[0.000]}\end{array}$ & $\begin{array}{l}3.66^{\star \star} \\
{[0.000]}\end{array}$ & $\begin{array}{l}3.68^{\star \star} \\
{[0.000]}\end{array}$ \\
\hline $\mathrm{H}_{0}: \xi_{t} \mathrm{CE}\left(p_{t}\right)$ & $\begin{array}{c}1.23 \\
{[0.113]}\end{array}$ & $\begin{array}{l}1.28 \\
{[0.104]}\end{array}$ & $\begin{array}{c}1.61^{(\star)} \\
{[0.057]}\end{array}$ & $\begin{array}{c}1.11 \\
{[0.136]}\end{array}$ \\
\hline $\begin{array}{l}\text { White's reality check } \\
\qquad \mathrm{H}_{0}: \xi_{t}^{o p t} \nsucceq p_{t}\end{array}$ & & & & $\begin{array}{c}\times^{\star} \\
{[0.03]}\end{array}$ \\
\hline
\end{tabular}

The modified Diebold-Mariano test is a test for equal ( $\sim$ ") predictive ability where the original Diebold-Mariano [1995] statistic is small-sample corrected according to Harvey et al. [1997]. Critical values are taken from a $t$-distribution with 39 degrees of freedom. The test for forecast encompassing or conditional efficiency (CE) is in the spirit of Chong and Hendry [1986]. The test statistic and the asymptotic distribution are taken from Harvey et al. [1998]. Finally, White's [2000] method checks whether the best indicator-based model (marked by " $\times$ ") is not superior ( $\not Z$ ") to the benchmark $p_{t}$. The stationary bootstrap (see Politis and Romano [1994]) is based on 10000 resamples where the smoothing parameter is given by $0.1 .{ }^{\star \star},{ }^{\star},{ }^{(\star)}$ mean rejection of the null hypothesis at the $1 \%, 5 \%$ and $10 \%$ level respectively; $p$-values are given in brackets.

Table 5, for the truly composite indices, the hypothesis that the indicatorbased forecast is conditionally efficient cannot be rejected at the 10 per cent level, whereas it is rejected for the Ifo series of manufacturers' assessment on inventory stocks. Hence, in order to predict inventory fluctuations without any loss of relevant information, it is obviously necessary to incorporate the Ifo series on retail and wholesale traders' inventory assessment.

Apart from the first publication of the Statistisches Bundesamt, the predictors under consideration result from some kind of specification search. Furthermore, the indicator-based forecasting models are estimated. Following the arguments of West [1996, 2001] and White [2000], both properties tend to distort the applicability of the asymptotic distributions of the test statistics. White's reality check is a simulation-based method of testing the predictive superiority to a benchmark and thereby taking into account the specification search previously undertaken. Whereas the benchmark is easily found with the first release of the national accounts, it is difficult to include the specification search within each class of models. For simplicity, in the set of forecasts, we only include the results of those indicator-based predictors 
which are the best choice within their specific class.

As reported in the last row of Table 5, the White's reality check confirms that forecasting with the unweighted average is best among the set of specifications under comparison. This comes as no surprise because the unweighted average provides the forecast with the lowest (root) mean squared error in the sample under investigation. However, the more important result is that, as the bootstrapped $p$-value indicates, indicator-based forecasts are (in terms of statistical significance) superior to the first figure reported by Statistisches Bundesamt.

All in all, the inventory-investment-to-GDP ratio first available in the national accounts is far from being a rational forecast of the "final" figure. Apart from a bias and serial correlation, information taken from the Ifo business survey helps to predict how inventory investment is revised. Furthermore, simple forecasting models based on (even trivial) composite indices amalgamating the Ifo series provide better forecasts of the "true" inventory fluctuations than the first release of the national accounts. At least in the sample under investigation, the statistical methods applied do not end up with a weighting scheme which outperforms a simple unweighted average of the Ifo series.

\section{Conclusion}

Using data from the Ifo business survey, we have sought to find a composite index of inventory fluctuations in Germany. Such an index seems to be necessary because the preliminary figures of changes in inventories published in the German national accounts are unreliable.

Owing to the process of compilation of quarterly national accounts, the first announcement of inventory investment reported by the Statistisches Bundesamt is more a product of lack of statistical information rather than a measure of firm behavior. However, after two years or so, when more detailed information is available, the time series of inventory investment shows features which are typically attributable to inventory fluctuations. Consequently, the "final" releases of the national accounts serve as a suitable reference for the German inventory cycle.

By applying standard time series methods in the time and frequency domain, we have shown that there is considerable comovement between the reference and the three Ifo series documenting manufacturers', retail traders' and wholesale traders' assessments of stockholdings. On a monthly basis, we have therefore constructed composite indices of inventory fluctuations by means of codependent cycle analysis (i.e. a method based on canonical correlations) and static factor modeling. In a recursive analysis, the variants have been evaluated with respect to the stability of the weighting schemes and the ability to forecast the "true" inventory fluctuations. We have found 
clear evidence that, regardless of which alternative is considered, the composite indices outperform the preliminary release of the national accounts. With respect to the stability of the weighting schemes, however, the codependent cycle analysis turns out to perform better than the static factor model approach.

The three Ifo series have been chosen because they are published monthly and provide specific information from sectors holding significant proportions of the aggregate inventory stock in Germany. However, this data set has some shortcomings. First, only West German retail and wholesale traders are captured in the Ifo business survey. Second, on a monthly basis, manufacturers are asked to assess the inventory stocks of finished goods only. Hence changes in the stocks of purchased material and supplies which also seem to be important sources of inventory fluctuations are not included in the composite indices. It is worth mentioning that the Ifo institute asks manufacturers to assess the stock of raw materials and the extent of potential shortages. However, these data are only collected on a quarterly basis.

\section{Appendices}

\section{A.1 Tests for Unit Roots in the Ifo Series}

In the sample from January 1980 to June 2003, we test for the presence of a unit root in the Ifo series under consideration. On the one hand, we apply the augmented Dickey-Fuller (ADF) test and the Phillips-Perron (PP) test. $^{35}$ In both test procedures, the null hypothesis is that the time series has a unit root. On the other hand, we carry out the procedure proposed by Kwiatkowski, Phillips, Schmidt, and Shin [1992] which tests the null of stationarity against nonstationary alternatives. Since no series is trending over time, the respective test equations do not exhibit a linear trend.

In the ADF test, the lag order is chosen such that no significant lagged difference is omitted from the test equation. For the PP and the KPSS test, an estimation of the so-called long-run variance (i.e. the spectrum at frequency zero) of the residual sequence is needed. We apply an estimator based on a Bartlett kernel whose bandwidth is determined using the automatic data-based method proposed by Newey and West [1994].

Table 6 reports the results of the unit root tests. At the $1 \%$ level, both the ADF and the PP test reject the presence of a unit root in the Ifo series of retail and wholesale traders' assessments of inventories. For the series of manufacturers' assessment, the PP test only rejects at the $10 \%$ level whereas the ADF test rejects at the $5 \%$ level. Using the KPSS procedure, the null of stationarity is rejected in neither case. We can therefore conclude that all Ifo series under consideration are stationary.

\footnotetext{
${ }^{35}$ For further details on the test statistics, see Hamilton [1994], Chapter 17, for instance.
} 
Table 6: Unit root tests of the Ifo series

\begin{tabular}{|c|cc|cc||cc||}
\hline Indicator & \multicolumn{2}{|c|}{ ADF } & \multicolumn{2}{|c||}{ PP } & \multicolumn{2}{c|}{ KPSS } \\
\hline manufacturers' inventories & $(5)$ & $-3.31^{\star}$ & $(11)$ & $-2.63^{(\star)}$ & $(14)$ & 0.20 \\
retail traders' inventories & $(3)$ & $-3.49^{\star \star}$ & $(11)$ & $-9.39^{\star \star}$ & $(13)$ & 0.32 \\
wholesale traders' inventories & $(2)$ & $-4.43^{\star \star}$ & $(10)$ & $-8.66^{\star \star}$ & $(13)$ & 0.36 \\
\hline
\end{tabular}

The numbers in parentheses indicate the lag length in the ADF procedure and the bandwidth parameter in the PP and KPSS procedures. MacKinnon [1991] critical values for the ADF and the PP tests are $-3.45,-2.87$ and -2.57 for significance at the $1 \%, 5 \%$ and $10 \%$ level respectively. For the KPSS test, the respective asymptotic values are 0.74 , 0.46 and $0.35 .{ }^{\star \star},{ }^{\star},{ }^{(\star)}$ mean rejection of the null hypothesis at the $1 \%, 5 \%$ and $10 \%$ level respectively.

\section{A.2 Structural Data Revisions}

During the 1990s, German national accounts data are subject to several important statistical breaks which might limit the comparability of different data vintages: In May 1999, the Statistisches Bundesamt published for the first time the national accounts statistics according to the principles agreed upon in the European System of Accounts 1995 (ESA 95). ${ }^{36}$ Until September 1995, no seasonally adjusted data for Germany as a whole had been released. ${ }^{37}$ As a consequence, whereas the final release is defined by the series of inventory investment as published in August 2003, i.e. for Germany as a whole and according to the ESA 95 principles, the first releases before May 1999 are measured according to the previous accounting standards (ESA 79), and additionally, the first releases before September 1995 refer to West Germany.

We are able to circumvent the problem of different territorial bases by using inventory investment as a percentage of GDP. As shown in Figure 9(a), regardless of which territorial basis is considered, the ratios do not differ significantly from one another. In contrast, Figure 9(b) shows that the switch to the new accounting standards obviously caused major changes in the shape of the time series. For the construction of a series of preliminary releases, however, only the final figure of each vintage is used. The first releases according to the different accounting standards can be compared only once, namely in the fourth quarter of 1998 which is the last data point in Figure 9(b). We do not find any big difference between the two. Let us assume that this would also hold for the other realizations where comparisons

\footnotetext{
${ }^{36}$ Details concerning the nature and the extent of revisions in the German national accounts are presented in Statistisches Bundesamt [1999a, 1999b].

${ }^{37}$ The impact of the change of the territorial basis on the national accounts figures, especially the problems this induced for seasonal adjustment, is documented in Deutsche Bundesbank [1995].
} 
Figure 9: Structural data revisions

(a) Unification

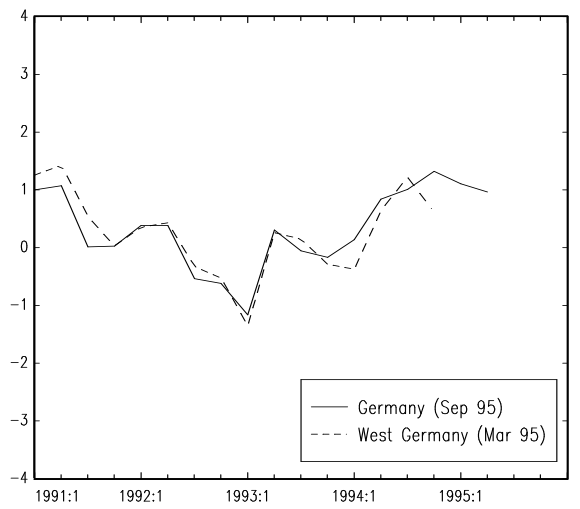

(b) Change in the accounting standards

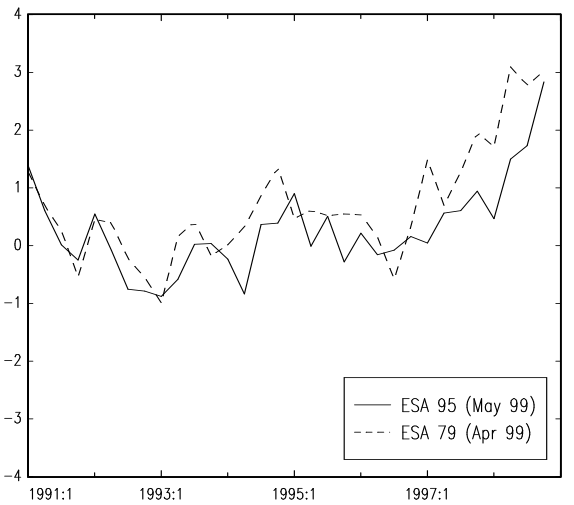

In the graphs, the inventory-investment-to-GDP ratios are plotted. The scale on the vertical axis is in per cent.

are not possible. Under these circumstances, we are able to use the first ESA 79 publications as if they were releases which are compiled according to the ESA 95 principles.

\section{References}

Abramovitz, Moses [1950], Inventories and Business Cycles, New York: National Bureau of Economic Research.

Ashley, Richard [2003], Statistically Significant Forecasting Improvements: How Much Out-of-Sample Data Is Likely Necessary?, International Journal of Forecasting 19: 229-239.

Baxter, Marianne and Robert G. King [1999], Measuring Business Cycles: Approximate Band-Pass Filters for Economic Time Series, Review of Economics and Statistics 81: 575-593.

Blinder, Alan S. [1981], Retail Inventory Behavior and Business Fluctuations, Brookings Papers on Economic Activity 1981, 2: 443-520.

Blinder, Alan S. and Douglas Holtz-Eakin [1986], Inventory Fluctuations in the United States since 1929, in: Gordon, Robert J. (ed.), The American Business Cycle: Continuity and Change, Chicago and London: The University of Chicago Press: 183-236. 
Blinder, Alan S. and Louis J. Maccini [1991], Taking Stock: A Critical Assessment of Recent Research on Inventories, Journal of Economic Perspectives 5: 73-96.

Braakmann, Albert [2003], Qualität und Genauigkeit der Volkswirtschaftlichen Gesamtrechnungen, Allgemeines Statistisches Archiv 87: 183-199.

Chong, Yock Y. and David F. Hendry [1986], Econometric Evaluation of Linear Macro-Economic Models, Review of Economic Studies 53: $671-690$.

Deutsche Bundesbank [1995], Ergebnisse der Volkswirtschaftlichen Gesamtrechnungen für Deutschland insgesamt, Monatsbericht Oktober 1995: 47-60.

Diebold, Francis X. and Roberto S. Mariano [1995], Comparing Predictive Accuracy, Journal of Business and Economic Statistics 13, 3: 253-263.

Döpke, Jörg and Enno Langfeldt [1997], Die Vorratsveränderungen im Rahmen von Konjunkturprognosen, Konjunkturpolitik 43: 344-377.

Doz, Catherine and Fabrice Lenglart [1999], Analyse Factorielle Dynamique: Test du Nombre de Facteurs, Estimation et Application à l'Enquête de Conjoncture dans l'Industrie, Annales d'Economie et de Statistique 54: 91-127.

Engle, Robert F. and Sharon Kozicki [1993], Testing for Common Features, Journal of Business and Economic Statistics 11: 369-395.

Gouriéroux, Christian and Irina Peaucelle [1992], Séries Codépendantes: Application à l'Hypothèse de Parité du Pouvoir d'Achat, Revue d'Analyse Economique 68: 283-304.

Granger, Clive W.J. [1966], The Typical Spectral Shape of an Economic Variable, Econometrica 34: 150-161.

Hamilton, James D. [1994], Time Series Analysis, Princeton and New Jersey: Princeton University Press.

Harvey, David I.; Stephen J. Leybourne and Paul Newbold [1997], Testing the Equality of Prediction Mean Squared Errors, International Journal of Forecasting 13: 281-291.

Harvey, David I.; Stephen J. Leybourne and Paul Newbold [1998], Tests for Forecast Encompassing, Journal of Business and Economic Statistics 16, 2: 254-259. 
Howrey, E. Philip [1984], Data Revision, Reconstruction, and Prediction: An Application to Inventory Investment, Review of Economics and Statistics 66: 384-393.

Knetsch, Thomas A. [2004], The Inventory Cycle of the German Economy, Economic Research Centre of the Deutsche Bundesbank: Discussion Paper 09/2004.

Kwiatkowski, Denis A.; Peter C.B. Phillips, Peter Schmidt and Yongcheol Shin [1992], Testing the Null Hypothesis of Stationarity Against the Alternative of a Unit Root: How Sure Are We That Economic Time Series Have a Unit Root?, Journal of Econometrics 54: $154-178$.

Lütkepohl, Helmut [1993], Introduction to Multiple Time Series Analysis, Second Edition, Berlin et al.: Springer.

MacKinnon, James G. [1991], Critical Values for Cointegration Tests, in: Engle, Robert F. and Clive W.J. Granger (eds.), Long-Run Economic Relationships: Readings in Cointegration, Oxford: Oxford University Press: 267-276.

Mankiw, N. Gregory; David E. Runkle and Matthew D. Shapiro [1984], Are Preliminary Announcements of the Money Stock Rational Forecasts?, Journal of Monetary Economics 14: 15-27.

Mankiw, N. Gregory and Matthew D. Shapiro [1986], News or Noise: An Analysis of GNP Revisions, Survey of Current Business 66, 5: $20-25$.

Metzler, Lloyd A. [1941], The Nature and Stability of Inventory Cycles, Review of Economics and Statistics 3: 113-129.

Moore, Geoffrey H. and Victor Zarnowitz [1986], The Development and Role of the National Bureau of Economic Research's Business Cycle Chronologies, in: Gordon, Robert J. (ed.), The American Business Cycle: Continuity and Change, Chicago and London: The University of Chicago Press: 735-779.

Newey, Whitney K. and Kenneth D. West [1987], A Simple Positive Semi-Definite, Heteroskedasticity and Autocorrelation Consistent Covariance Matrix, Econometrica 55: 703-708.

Newey, Whitney K. and Kenneth D. West [1994], Automatic Lag Selection in Covariance Matrix Estimation, Review of Economic Studies, 61: 631-653. 
Oppenländer, Karl H. and Günter Poser (eds.) [1994], Handbuch der Ifo-Umfragen, Berlin and Munich: Duncker und Humblot.

Peña, Daniel and George E.P. Box [1987], Identifying a Simplifying Structure in Time Series, Journal of the American Statistical Association 82: 836-843.

Politis, Dimitris N. and Joseph P. Romano [1994], The Stationary Bootstrap, Journal of the American Statistical Association 89: 13031313.

Ramey, Valerie A. and Kenneth D. West [1999], Inventories, in: Taylor, John B. and Michael Woodford (eds.), Handbook of Macroeconomics, Volume 1, Amsterdam: Elsevier Science Publishers: 863-923.

Statistisches Bundesamt [1999a], Revision der Volkswirtschaftlichen Gesamtrechnungen 1999-Anlaß, Konzeptänderungen und neue Begriffe, Wirtschaft und Statistik 4/1999: 257-281.

Statistisches Bundesamt [1999b], Revision der Volkswirtschaftlichen Gesamtrechnungen 1991 bis 1998, Wirtschaft und Statistik 6/1999: 449-478.

Statistisches Bundesamt [2003], Volkswirtschaftliche Gesamtrechnungen: Inlandsprodukt nach ESVG 1995 - Methoden und Grundlagen -, Fachserie 18/Reihe S.22, Stuttgart: Metzler-Poeschel.

Swanson, Norman R.; Eric Ghysels and Myles Callan [1999], $A$ Multivariate Time Series Analysis of the Data Revision Process for Industrial Production and the Composite Leading Indicator, in: Engle, Robert F. and Halbert White (eds.), Cointegration, Causality, and Forecasting-A Festschrift in Honour of Clive W.J. Granger, Oxford and New York: Oxford University Press: 45-75.

Tiao, George C. and Ruey S. Tsay [1989], Model Selection in Multivariate Time Series, Journal of the Royal Statistical Society B 51: 153-213.

Vahid, Farshid and Robert F. Engle [1997], Codependent Cycles, Journal of Econometrics 80: 199-221.

West, Kenneth D. [1996], Asymptotic Inference about Predictive Ability, Econometrica 64, 5: 1067-1084.

West, Kenneth D. [2001], Tests for Forecast Encompassing When Forecasts Depend on Estimated Regression Parameters, Journal of Business and Economic Statistics 19, 1: 29-33. 
White, Halbert [2000], A Reality Check for Data Snooping, Econometrica $68,5:$ 1097-1126.

Zarnowitz, Victor [1985], Recent Work on Business Cycles in Historical Perspective: A Review of Theories and Evidence, Journal of Economic Literature 23: 523-580. 


\section{CESifo Working Paper Series}

(for full list see www.cesifo.de)

1136 Robert Dekle and Kenneth Kletzer, Deposit Insurance, Regulatory Forbearance and Economic Growth: Implications for the Japanese Banking Crisis, February 2004

1137 Takatoshi Ito and Kimie Harada, Bank Fragility in Japan, 1995-2003, February 2004

1138 Kunio Okina and Shigenori Shiratsuka, Policy Duration Effect under Zero Interest Rates: An Application of Wavelet Analysis, February 2004

1139 Francine D. Blau and Lawrence M. Kahn, Do Cognitive Test Scores Explain Higher U.S. Wage Inequality?, February 2004

1140 Michael Rauscher, Economic Growth and Tax-Competing Leviathans, February 2004

1141 Ernst Fehr and Jean-Robert Tyran, Money Illusion and Coordination Failure, February 2004

1142 Ingo Vogelsang, Network Utilities in the U.S. - Sector Reforms without Privatization, March 2004

1143 Marc-Andreas Muendler, Estimating Production Functions When Productivity Change is Endogenous, March 2004

1144 Sascha O. Becker, Samuel Bentolila, Ana Fernandes, and Andrea Ichino, Job Insecurity and Children's Emancipation, March 2004

1145 Pascalis Raimondos-Møller and Alan D. Woodland, Non-Preferential Trading Clubs, March 2004

1146 Robert Fenge and Matthias Wrede, EU Regional Policy: Vertical Fiscal Externalities and Matching Grants, March 2004

1147 Chi-Yung Ng and John Whalley, Geographical Extension of Free Trade Zones as Trade Liberalization: A Numerical Simulation Approach, March 2004

1148 Marc-Andreas Muendler, Trade, Technology, and Productivity: A Study of Brazilian Manufacturers, 1986-1998, March 2004

1149 Eugene Beaulieu, Vivek H. Dehejia, and Hazrat-Omar Zakhilwal, International Trade, Labour Turnover, and the Wage Premium: Testing the Bhagwati-Dehejia Hypothesis for Canada, March 2004

1150 Giorgio Brunello and Francesca Gambarotto, Agglomeration Effects on EmployerProvided Training: Evidence from the UK, March 2004 
1151 S. Brock Blomberg, Gregory D. Hess, and Athanasios Orphanides, The Macroeconomic Consequences of Terrorism, March 2004

1152 Bodo Sturm and Joachim Weimann, Unilateral Emissions Abatement: An Experiment, March 2004

1153 Wolfgang Ochel, Welfare-to-Work Experiences with Specific Work-First Programmes in Selected Countries, March 2004

1154 Jan K. Brueckner and Eric Pels, European Airline Mergers, Alliance Consolidation, and Consumer Welfare, March 2004

1155 Aaron Tornell, Frank Westermann, and Lorenza Martínez, NAFTA and Mexico's Economic Performance, March 2004

1156 George Economides, Sarantis Kalyvitis, and Apostolis Philippopoulos, Do Foreign Aid Transfers Distort Incentives and Hurt Growth? Theory and Evidence from 75 Aidrecipient Countries, March 2004

1157 Robert Fenge and Volker Meier, Are Family Allowances and Fertility-related pensions Siamese Twins?, March 2004

1158 Bruno S. Frey, Simon Luechinger, and Alois Stutzer, Valuing Public Goods: The Life Satisfation Approach, March 2004

1159 Jerome L. Stein and Guay C. Lim, Asian Crises: Theory, Evidence, Warning-Signals, March 2004

1160 Romain Ranciere, Aaron Tornell, and Frank Westermann, Crises and Growth: A ReEvaluation, March 2004

1161 Assaf Razin and Efraim Sadka, Transparency, Specialization and FDI, March 2004

1162 Ludger Woessmann, How Equal Are Educational Opportunities? Family Background and Student Achievement in Europe and the United States, March 2004

1163 B.M.S. van Praag and Barbara E. Baarsma, Using Happiness Surveys to Value Intangibles: The Case of Airport Noise, March 2004

1164 Aaron Tornell, Frank Westermann, and Lorenza Martínez, The Positive Link Between Financial Liberalization, Growth, and Crises, March 2004

1165 Helge Berger and Carsten Hefeker, One Country, One Vote? Labor Market Structure and Voting Rights in the ECB, March 2004

1166 Clemens Fuest and Martin Kolmar, A Theory of User-Fee Competition, March 2004

1167 Friedrich Schneider and Robert Klinglmair, Shadow Economies around the World: What Do We Know?, April 2004 
1168 Horst Raff and Nicolas Schmitt, Exclusive Dealing and Common Agency in International Markets, April 2004

1169 M. Hashem Pesaran and Allan Timmermann, Real Time Econometrics, April 2004

1170 Sean D. Barrett, Privatisation in Ireland, April 2004

1171 V. Anton Muscatelli, Patrizio Tirelli and Carmine Trecroci, Can Fiscal Policy Help Macroeconomic Stabilisation? Evidence from a New Keynesian Model with Liquidity Constraints, April 2004

1172 Bernd Huber and Marco Runkel, Tax Competition, Excludable Public Goods and User Charges, April 2004

1173 John McMillan and Pablo Zoido, How to Subvert Democracy: Montesinos in Peru, April 2004

1174 Theo Eicher and Jong Woo Kang, Trade, Foreign Direct Investment or Acquisition: Optimal Entry Modes for Multinationals, April 2004

1175 Chang Woon Nam and Doina Maria Radulescu, Types of Tax Concessions for Attracting Foreign Direct Investment in Free Economic Zones, April 2004

1176 M. Hashem Pesaran and Andreas Pick, Econometric Issues in the Analysis of Contagion, April 2004

1177 Steinar Holden and Fredrik Wulfsberg, Downward Nominal Wage Rigidity in Europe, April 2004

1178 Stefan Lachenmaier and Ludger Woessmann, Does Innovation Cause Exports? Evidence from Exogenous Innovation Impulses and Obstacles, April 2004

1179 Thiess Buettner and Johannes Rincke, Labor Market Effects of Economic Integration The Impact of Re-Unification in German Border Regions, April 2004

1180 Marko Koethenbuerger, Leviathans, Federal Transfers, and the Cartelization Hypothesis, April 2004

1181 Michael Hoel, Tor Iversen, Tore Nilssen, and Jon Vislie, Genetic Testing and Repulsion from Chance, April 2004

1182 Paul De Grauwe and Gunther Schnabl, Exchange Rate Regimes and Macroeconomic Stability in Central and Eastern Europe, April 2004

1183 Arjan M. Lejour and Ruud A. de Mooij, Turkish Delight - Does Turkey’s accession to the EU bring economic benefits?, May 2004

1184 Anzelika Zaiceva, Implications of EU Accession for International Migration: An Assessment of Potential Migration Pressure, May 2004 
1185 Udo Kreickemeier, Fair Wages and Human Capital Accumulation in a Global Economy, May 2004

1186 Jean-Pierre Ponssard, Rent Dissipation in Repeated Entry Games: Some New Results, May 2004

1187 Pablo Arocena, Privatisation Policy in Spain: Stuck Between Liberalisation and the Protection of Nationals' Interests, May 2004

1188 Günter Knieps, Privatisation of Network Industries in Germany: A Disaggregated Approach, May 2004

1189 Robert J. Gary-Bobo and Alain Trannoy, Efficient Tuition Fees, Examinations, and Subsidies, May 2004

1190 Saku Aura and Gregory D. Hess, What's in a Name?, May 2004

1191 Sjur Didrik Flåm and Yuri Ermoliev, Investment Uncertainty, and Production Games, May 2004

1192 Yin-Wong Cheung and Jude Yuen, The Suitability of a Greater China Currency Union, May 2004

1193 Inés Macho-Stadler and David Pérez-Castrillo, Optimal Enforcement Policy and Firms' Emissions and Compliance with Environmental Taxes, May 2004

1194 Paul De Grauwe and Marianna Grimaldi, Bubbles and Crashes in a Behavioural Finance Model, May 2004

1195 Michel Berne and Gérard Pogorel, Privatization Experiences in France, May 2004

1196 Andrea Galeotti and José Luis Moraga-González, A Model of Strategic Targeted Advertising, May 2004

1197 Hans Gersbach and Hans Haller, When Inefficiency Begets Efficiency, May 2004

1198 Saku Aura, Estate and Capital Gains Taxation: Efficiency and Political Economy Consideration, May 2004

1199 Sandra Waller and Jakob de Haan, Credibility and Transparency of Central Banks: New Results Based on Ifo's World Economicy Survey, May 2004

1200 Henk C. Kranendonk, Jan Bonenkamp, and Johan P. Verbruggen, A Leading Indicator for the Dutch Economy - Methodological and Empirical Revision of the CPB System, May 2004

1201 Michael Ehrmann, Firm Size and Monetary Policy Transmission - Evidence from German Business Survey Data, May 2004

1202 Thomas A. Knetsch, Evaluating the German Inventory Cycle - Using Data from the Ifo Business Survey, May 2004 